ELABORACIÓN DE PLAN DE NEGOCIO PARA LA EMPRESA LUZINDA S.A.S

PRESENTADO POR

LEMIS MARGARITA CASTRO CASTRO

NATHALIA BARRERO CRISTANCHO

\author{
UNIVERSIDAD SANTO TOMÁS AQUINO \\ FACULTAD DE ADMINISTRACIÓN DE EMPRESAS \\ PLAN DE NEGOCIOS \\ AGOSTO 2017 \\ BOGOTA D.C.
}




\title{
ELABORACIÓN DE PLAN DE NEGOCIO PARA LA EMPRESA LUZINDA S.A.S
}

\section{PRESENTADO POR}

\author{
LEMIS MARGARITA CASTRO CASTRO \\ NATHALIA BARRERO CRISTANCHO
}

TUTOR

ELIAS RODRİGUEZ PARRA

UNIVERSIDAD SANTO TOMÁS

FACULTAD DE ADMINISTRACIÓN DE EMPRESAS

PLAN DE NEGOCIOS

AGOSTO 2017

BOGOTA D.C 
NOTA DE ACEPTACIÓN

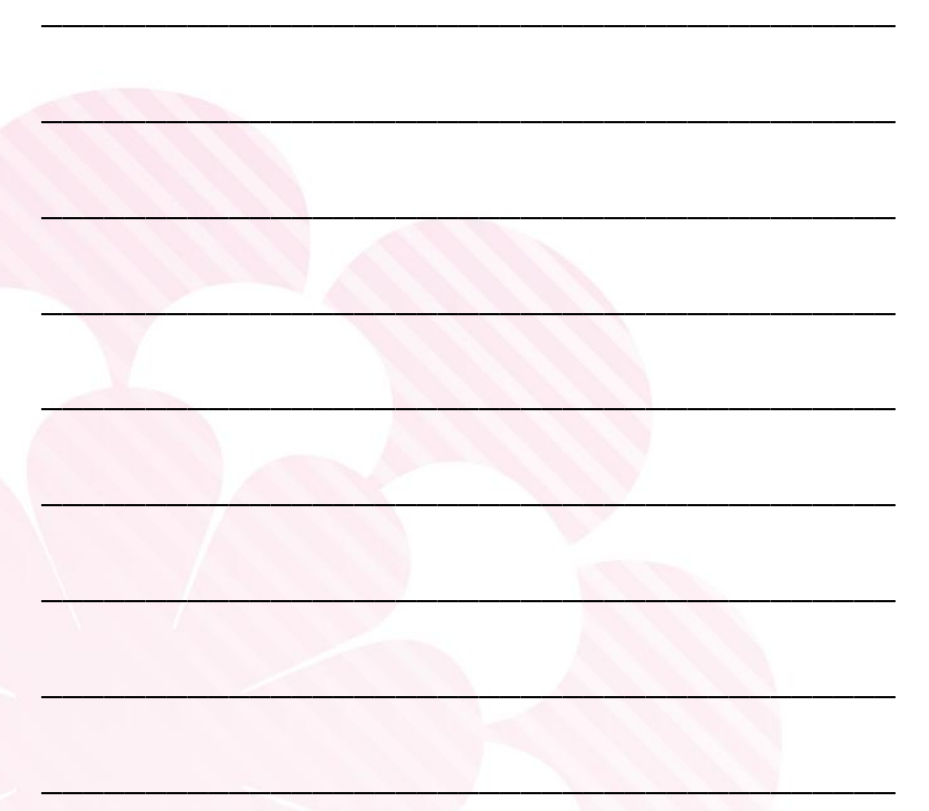

FIRMA DEL JURADO

FIRMA DEL JURADO 


\section{DEDICATORIA}

Este trabajo de grado está dedicado a nuestros padres ya que, gracias a su apoyo y buenos consejos, estamos realizando este sueño.

A nuestros hermanos por su voz de aliento en días difíciles quienes con su optimismo nos motivaron para seguir adelante.

A nuestros sobrinos que son el motor para dar lo mejor de nosotras y ser ejemplo para sus vidas.

$\mathrm{Y}$ a todos los amigos y familiares que creyeron y tuvieron fe en nosotras.

A nuestras parejas que nos han apoyado con su amor, apoyo, compañía paciencia y optimismo.

\section{LEMIS MARGARITA CASTRO CASTRO Y NATHALIA BARRERO CRISTANCHO}




\section{AGRADECIMIENTOS}

Nuestros agradecimientos son principalmente a Dios por permitirnos llegar a este punto.

De corazón gracias a nuestro tutor el profesor Elías Rodríguez, por compartir con nosotras sus conocimientos y acompañamiento durante la realización del presente trabajo.

A la universidad San Tomás por darnos las herramientas necesarias para llegar a ser profesionales íntegros para el país, en especial a los docentes que con su don de servicio dejaron huellas en nuestro ser, a la secretaria de la facultad de Administración de Empresas

Sandra Milena Castillo Camacho, quien con su carisma y alegría siempre dio solución a nuestras inquietudes, a nuestras familias y parejas por su amor, apoyo y compañía incondicional. 
RESUMEN EJECUTIVO _ 11

INTRODUCCIÓN __ 11

JUSTIFICACIÒN _ 12

DESCRIPCIÒN DEL PROBLEMA___ 13

Idea del negocio _ 13

OBJETIVOS _ 14

Objetivo general __ 14

Objetivos específicos__ 14

CONCEPTO DEL PRODUCTO O SERVICIO__ 15

Metodología _ـ 16

PLANEACIÓN ESTRATÉGICA __ 16

Misión__ 16

Visión — 16

Valores — 17

Objeticos estratégicos _ 17

Objeticos tácticos — 17

Objetivos operacionales _ 18

Filosofía del negocio___ 18

CONCEPTO DEL PRODUCTO O SERVICIO __ 19

Identificación detallada de las necesidades __ 19

Presentación detallada de las especificaciones del producto o servicio ___ 19

Uso y manejo del producto o servicio___ 20

Imagen, marca, logo y slogan del producto o servicio __ 20

RESUMEN DEL MODELO DE NEGOCIO__ 21

ESTUDIO DE MERCADO _ 22 
Sector económico

Calzado en Bogotá __ 23

Futuro general del sector — 26

Análisis económico sectorial. Análisis de la oferta. Cuantos - quienes - donde - que como - Comparación — 28

Análisis de la demanda - social - demográfica - económica y cultural ___ 30

PRESENTACION DE RESULTADOS__ 32

PERFIL DEL CLIENTE _ 43

SEGMENTACIÓN DEL CLIENTE __ 44

PLAN DE MERCADEO _ 45

Estrategias de distribución:___ 45

Publicidad: _ 46

Estrategias de comunicación:___ 46

Fidelización: _ 46

Postventa - servicio al cliente: __ 47

ESTUDIO DE OPERACIONES _ 47

Descripción del proceso de fabricación ___ 47

DIAGRAMA DE FLUJO _ _ 49

Inversión en infraestructura _ 50

Inversión en capital de trabaja __ 51

Costos de mano de obra _ 52

ESTUDIO ORGANIZACIONAL _ 55

Organigrama _ 55

Manual de funciones __ 56

REQUISITOS LEGALES _ 62

GASTOS ADMINISTRATIVOS___ 65

Metodologías de Motivación __ 66

Mecanismos de Liderazgo __ 66

ESTUDIO FINANCIERO __ 67

Políticas financieras _ 67

Punto de equilibrio __ 67

Asignación de precios__ 69 
Presupuesto de ventas

Presupuesto de fabricación __ 71

Estado de costos _ 72

Flujo de caja __ 73

Estado de resultados _ 75

Balance general__ 76

INDICADORES FINANCIEROS _ 77

Interpretación de los indicadores __ 78

CONCLUSIONES _ 80

BIBLIOGRAFIA Y WEBGRAFIA ___ 82

ANEXOS

Presupuestos de Materias primas __ 84

Plan de fabricaciòn __ 86 


\section{TABLA DE ILUSTRACIONES}

Ilustración 1. Ficha técnica del producto _ـ 19

Ilustración 2. Logo Luzinda _ 20

Ilustración 3. Número de empresas ubicadas en Chapinero ___ 29

Ilustración 4.Edificios de Chapinero ___ 31

Ilustración 5. Encuesta zapatos Luzinda __ 33

Ilustración 6. Resultado calculadora muestral __ 35

Ilustración 7 Resultado calculadora muestral 2 __ 36

Ilustración 8. Resultados encuesta - Estrato Socio Económico___ 36

Ilustración 9. Resultados encuesta - Nivel escolaridad__ 37

Ilustración 10. Resultados encuesta-Redes sociales _ 37

Ilustración 11. Resultados encuesta - Frecuencia de compra___ 38

Ilustración 12. Resultados encuesta - Dinero a invertir _ 39

Ilustración 13. Resultados encuesta - factores predominantes a la hora de comprar __ 39

Ilustración 14. Resultados encuesta - Agrado por los zapatos de tacón corrido___ 40

Ilustración 15. Resultados encuesta - Materiales de preferencia __ 40

Ilustración 16. Resultados encuesta - Mujeres que comprarían el producto___ 41

Ilustración 17. Resultados encuesta-Seguridad que genera el producto__ 41

Ilustración 18. Proyecciones de población Mujeres 2018__ 44

Ilustración 19. Diagrama de flujo __ 49

Ilustración 20. Distribución de planta___ 50

Ilustración 21. Inversión en equipos __ 51

Ilustración 23. Nòmina operarios _ 52

Ilustración 24. Nómina Director de producción _ 53

Ilustración 25. Nómina administrativa___ 53

Ilustración 26. Nómina de ventas__ 54

Ilustración 27. Organigrama__ 55

Ilustración 28. Manual de funciones __ 56

Ilustración 29. Requisitos inscripción en cámara y comercio___ 64

Ilustración 30. Relación de gastos administrativos __ 65

Ilustración 31. Relación de otros gastos___ 65

Ilustración 32. Política de compras___ 67

Ilustración 33. Punto de equilibrio___ 67

Ilustración 34. Estado de Resultados Operativo y financiero ___ 68

Ilustración 35. Dinero a invertir a la hora de comprar zapatos__ 69

Ilustración 36. Comportamiento de la inflación _ 70

Ilustración 37. Ventas reales del sector___ 70 
Ilustración 38. Proyección de ventas Luzinda SAS ___ 71

Ilustración 39. Presupuesto de fabricación __ 72

Ilustración 40. Estado de costos___ 73

Ilustración 41. Flujo de caja ___ 74

Ilustración 42. Saldos finales disponibles __ 74

Ilustración 43. Estado de resultados ___ 75

Ilustración 44. Utilidades del ejercicio ___ 76

Ilustración 45. Balance General ___ 76

Ilustración 46. Indicadores de liquidez ___ 77

Ilustración 47. Indicadores de rentabilidad___ 77

Ilustración 48. TIR__ 78

Ilustración 49.VPN__ 78 


\section{RESUMEN EJECUTIVO}

\section{INTRODUCCIÓN}

El presente trabajo es una recopilación de los conocimientos adquiridos durante la formación profesional en la carrera de Administración de Empresas, donde siguiendo unos parámetros se elaboró un Business plan para la empresa Luzinda, la idea de negocio surge en la necesidad de sentir seguridad al momento de llevar ciertos objetos de valor, para ello se crea un zapato con bolsillo secreto de seguridad, se crea la misión, la visión, objetivos generales y específicos, valores, así como la estructura de la organización (organigrama).

Se realiza una investigación del comportamiento, situación y futuro del sector del calzado en la ciudad de Bogotá, mostrando como las empresas de este sector han logrado mantenerse y apoyarse, haciendo frente al contrabando y al calzado barato y de mala calidad proveniente de Asia.

Se tomó una muestra del sector de chapinero mediante la realización de una encuesta, con el fin de saber si la idea de negocio es atractiva, precio dispuesto a pagar, redes sociales preferibles para conocer de un producto, entre otras.

Elaboración estado de resultados y balance general, proyectados a 5 años, así como también de la nómina, presupuesto de ventas, de mano de obra, de materiales, determinación del punto de equilibrio y selección de indicadores de evaluación financiera. 


\section{JUSTIFICACIÒN}

La elaboración de este proyecto empresarial tiene como fin aplicar los conocimientos que hemos adquirido en nuestra formación como administradoras de empresas de la universidad santo tomas, y así crear una empresa dedicada a fabricar y comercializar zapatos con bolsillo secreto.

Siendo la ciudad de Bogotá la urbe en la que se presentan los mayores índices de hurto a personas con unas cifras de 994.000 frente a un total de 1.997 .000 en 28 ciudades de Colombia, para el año 2015 un total de 514.000 mujeres desde los 15 años en adelante fueron víctimas de robo, donde el dinero en efectivo, tarjetas y documentos personales presentaron un total de 450.000 reportes en el mismo año frente a un total de 903.000 casos dentro de la medición (datos tomados de Encuesta de convivencia y seguridad ciudadana del Dane).

Por lo anterior la mujer de hoy en el desarrollo de las diferentes facetas a las que se enfrenta en su vida cotidiana, se ve en la necesidad de proteger sus objetos de valor como el dinero, guardándolos en diferentes partes del cuerpo causándole incomodidad o afecciones en la piel, de allí surge la idea de crear un zapato con tacón con compartimento secreto, en el cual puedan guardarse joyas pequeñas o dinero mientras la mujer se traslada de un lugar a otro.

Los zapatos son una prenda de vestir de uso diario, en el caso de las mujeres se tienen varios pares de zapatos de diferente color, textura o material, ya que por lo general las mujeres buscan que coincidan con su vestuario o los accesorios que va a usar, por tanto, 
además de ser una prenda para vestir diaria llega a ser un accesorio con el que la mujer espera lucir bien en su día a día

\section{DESCRIPCIÒN DEL PROBLEMA}

En vista de los altos índices de inseguridad, existe la necesidad por parte de la población femenina de proteger aquellos artículos de valor que deben transportar a diario o de manera ocasional, como por ejemplo joyas o dinero.

Encontramos como oportunidad de negocio la creación de un zapato con un bolsillo secreto en el tacón que permita guardar aquellos artículos mientras que las mujeres se encuentran en la calle o en un medio de transporte público.

\section{Idea del negocio}

Zapato con tacón removible con bolsillo secreto de seguridad. 


\section{OBJETIVOS}

\section{Objetivo general}

Desarrollar un plan de negocios para la producción y comercialización de un zapato con bolsillo secreto en la ciudad de Bogotá.

\section{Objetivos específicos}

- Realizar un estudio de mercados en la localidad de Chapinero en la ciudad de Bogotá, con el fin de determinar la viabilidad de la creación y venta del zapato.

- Diseñar un zapato cómodo que se ajuste a las necesidades de la mujer de hoy.

- Generar mayor seguridad a la mujer para llevar sus objetos pequeños de valor con confianza y tranquilidad. 


\section{CONCEPTO DEL PRODUCTO O SERVICIO}

El calzado se origina en la necesidad de proteger el pie de la intemperie o de accidentes por las texturas de los terrenos y sus relieves.

Con el pasar del tiempo se puede ver que este se va transformando en un accesorio más en la vestimenta, y que a la vez de satisfacer las necesidades que le dieron origen, debe ahora cumplir con unas funciones estéticas, por lo que vemos en los últimos años que el calzado se adecua a una funcionalidad especifica o a una situación.

El proceso de la elaboración de los zapatos sigue siendo un trabajo de tipo artesanal en el que se requiere mucho de la mano de obra, a la vez que su elaboración requiere de muchos procesos que hacen que este accesorio sea una obra de arte y que en oportunidades pasa a ser el protagonista de la moda.

El prototipo es un zapato con tacón de mujer, diseñado con un compartimiento secreto en el cual las mujeres puedan guardar objetos de valor tales como joyas o dinero, con el fin de generar en las mujeres mayor seguridad mientras transitan por la calle o se movilizan en el transporte público.

El prototipo es un zapato de calidad, con materiales resistentes y de durabilidad, cuyo componente básico será el cuero, plantilla desodorante de acción triple, que tiene un alto poder de absorción del sudor y del mal olor y diferentes tipos de accesorios para que sea una prenda llamativa (cremallera, aros de metal, piedras, etc.). 


\section{Metodología}

La metodología a utilizar es la aplicación de todos los lineamientos establecidos por la universidad desde el inicio para el desarrollo del plan de negocios.

Por otro lado, poner en práctica todos los conocimientos adquiridos durante la carrera de administración de empresas en la universidad Santo Tomás, en investigación de mercados, creación de empresas y emprendimiento, proyección de ventas, entre otros, además del apoyo en una herramienta primaria para la investigación, como lo es la encuesta, con la cual se pretende conocer que tan atractivo resulta el producto Luzinda para la población de la localidad de Chapinero en la ciudad de Bogotá.

\section{PLANEACIÓN ESTRATÉGICA}

\section{Misión}

Luzinda SAS es una empresa dedicada a la producción y comercialización de calzado para dama con el cual se busca brindar seguridad y confort a nuestros clientes, mediante la utilización de materiales de calidad y la creación de bolsillos secretos en el zapato que sirve para guardar objetos pequeños de valor.

\section{Visión}

Para 2019 Luzinda SAS será reconocida como una empresa que trabaja por el bienestar y seguridad de la mujer y estará posicionada como la marca preferida en los sectores de Chapinero, Teusaquillo, Kennedy de la ciudad de Bogotá. 


\section{Valores}

- Honestidad: Ser transparentes en nuestros procesos productivos y contables.

- Respeto: Actuar con respecto por nuestro cliente interno y externo, teniendo claro que ambos son parte fundamental de nuestro existir.

- Responsabilidad: Cumpliendo con nuestro deber y entregando un producto de calidad, utilizando procesos eco amigables.

- Servicio: Ofrecer un servicio amable que generaré confianza y agregue valor a nuestros clientes.

\section{Objeticos estratégicos}

$\checkmark$ Crear un producto de calidad, atractivo e innovador.

$\checkmark$ Compra de materia prima de calidad que permita obtener un producto de calidad

$\checkmark$ Compra de la maquinaria necesaria para la fabricación optima del producto

\section{Objeticos tácticos}

$\checkmark$ Crear recordación del producto en los clientes

$\checkmark$ Mantener canales de comunicación permanentes con nuestros clientes

$\checkmark$ Cumplir con los tiempos de entrega. 


\section{Objetivos operacionales}

$\checkmark$ Se generarán espacios para pausas activas, cuyo fin será no solamente la integración de los funcionarios, sino que se propenderán por el bienestar físico y mental de los colaboradores.

$\checkmark$ Se hará reconocimiento al empleado del mes otorgando un incentivo en alianza con la caja de compensación.

$\checkmark$ Capacitación permanente de los empleados, apoyados con el SENA y las cajas de compensación.

$\checkmark$ Contar con un espacio adecuado para la operación, que cuente con una buena iluminación y ventilación.

$\checkmark$ Dotar a los funcionarios de los elementos de protección personal correspondientes a su labor.

\section{Filosofía del negocio}

Luzinda es una empresa dedicada a la elaboración y producción de calzado femenino, que promueve la utilización de calzado de calidad, se basa en el respeto, la sana competencia, la transparencia en sus procesos, creé en la responsabilidad social como medio para el bienestar y desarrollo de la comunidad. 


\section{CONCEPTO DEL PRODUCTO O SERVICIO}

\section{Identificación detallada de las necesidades}

Luzinda nace en la necesidad de las mujeres de la vida actual que cumplen diferentes roles en su día a día, son madres, estudiantes empleadas, muchas de ellas teniéndose que enfrentar a la inseguridad, por ello Luzinda es una herramienta que le brinda seguridad para transportar objetos pequeños de valor.

Presentación detallada de las especificaciones del producto o servicio

Ilustración 1. Ficha técnica del producto

\begin{tabular}{|c|l|}
\hline Nombre del producto & Luzinda \\
\hline Descripción del producto & Zapato con bolsillo secreto \\
\hline \multicolumn{1}{|c|}{ Característica Información } \\
\hline Material & Cuero sintético \\
\hline Color & Café, Negro, Azul, Rojo, Beige, etc. \\
\hline Precauciones & Evitar el contacto con detergentes fuertes, no sumergir en agua, \\
& limpiar con un paño suave y crema de mano. \\
\hline Necesidades que & Luzinda, desea satisfacer en las mujeres una necesidad, por medio \\
& de uno de los artículos fundamentales en su vestuario diario. El \\
& zapato con bolsillo secreto permite transportar objetos pequeños de \\
& el zapato. \\
\hline
\end{tabular}




\begin{tabular}{|c|l|}
\hline Perfil del consumidor: & $\begin{array}{l}\text { Mujeres desde los 15 años en delante que perciban desde 1 SMLV } \\
\text { en adelante. }\end{array}$ \\
\hline $\begin{array}{c}\text { Diferencias frente a los } \\
\text { productos sustitutos }\end{array}$ & $\begin{array}{l}\text { Bolsillo secreto que resulta ser una herramienta útil para la mujer en } \\
\text { el desarrollo de sus actividades diarias y en los diferentes roles a los } \\
\text { que se enfrenta en la actualidad (estudiantes, empresarias, } \\
\text { empleadas, madres de familia, etc.) }\end{array}$ \\
\hline
\end{tabular}

Fuente: Autoras

\section{Uso y manejo del producto o servicio}

Los zapatos Luzinda cuentan con un bolsillo secreto en el tacón del zapato, al cual se puede acceder por la parte interna del mismo, levantando la plantilla para introducir objetos pequeños de valor como un anillo o cadena, etc., después de esto se baja la suela colocándola en posición horizontal y luego de guardar el objeto la persona se coloca su par de zapatos y amarra los cordones.

\section{Imagen, marca, logo y slogan del producto o servicio}

\section{"Luce Linda y segura con Luzinda"}

Ilustración 2. Logo Luzinda

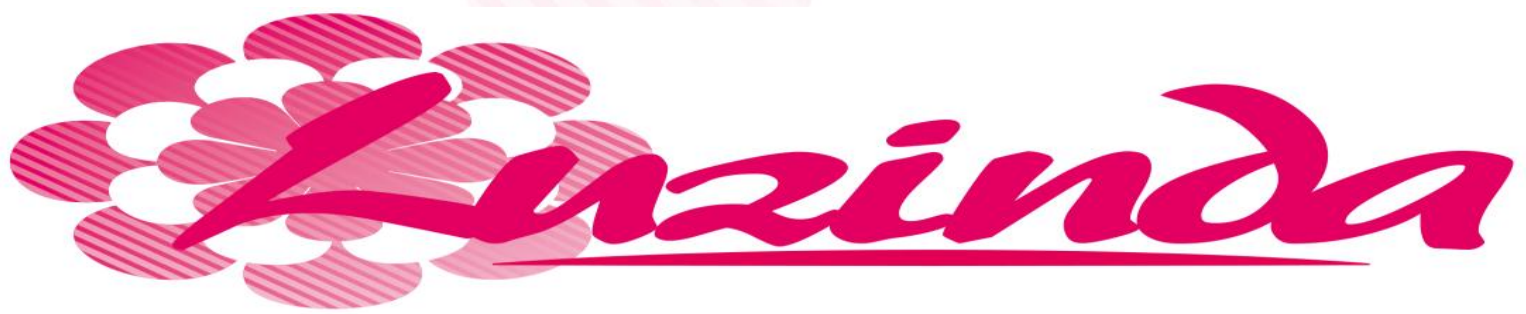

Fuente: Autoras 


\section{Resumen del modelo de negocio}

- Socios Clave: Proveedores del sector del Restrepo, redes sociales.

- Actividades Clave: Fabricación y comercialización de zapatos con bolsillo secreto. Dar a conocer los zapatos Luzinda en el mercado. Responder los requerimientos de los clientes.

- Recursos Clave: Personal con conocimiento en diseño, corte, costura y montaje de zapatos.

Página Web: https://zapatosluzinda.wixsite.com/luzinda

Utilización de redes sociales: Facebook, Instagram, YouTube. Local

- Propuesta de Valor: Creación de un zapato con un bolsillo secreto en el tacón que permita guardar aquellos artículos mientras que las mujeres se encuentran en la calle o en un medio de transporte público.

- Relación con Clientes: Comunicación directa con el cliente a través de las redes sociales y pagina web.

- Segmentación de clientes: Mujeres de 15 años en adelante, con ingresos mensuales desde un SMLV, inicialmente ubicadas en el sector de chapinero en la ciudad de Bogotá.

- Fuentes de ingresos: Resultado de las ventas de los zapatos. 


\section{ESTUDIO DE MERCADO}

Sector económico

Luzinda es una empresa dedicada a la fabricación y comercialización de calzado para dama, por tanto, es una empresa que participa en el sector de manufactura de la industria del cuero.

Los códigos CIUU con los que se identifica Luzinda son:

1521: Fabricación de calzado de cuero y piel, con cualquier tipo de suela.

4772: Comercio al por menor de todo tipo de calzado y artículos de cuero y sucedáneos del cuero en establecimientos especializados

Tomado de: http://linea.ccb.org.co/descripcionciiu/

El sector colombiano de manufacturas en cuero se ha caracterizado por su capacidad de producción y de adaptación a las demandas de los compradores, se ha ido tecnificando a medida que implementa nuevas tecnologías a sus empresas para mejorar procesos de producción; además, cuenta con una trayectoria exportadora importante en mercados como Venezuela, Ecuador, Panamá y Costa Rica.

En Colombia la cadena de cuero, calzado e industria marroquinera depende en gran medida de la matanza de ganado bobino del cual se adquiere gran parte de la oferta de cuero y pieles. A pesar de ello esta oferta no puede ser aprovechada por completo, esto por el bajo cuidado que se le da al cuero en la etapa de levante del ganado vacuno y durante su sacrificio. Esto se debe a la escaza capacitación que existe en el sector ganadero en el manejo de los cueros y las pieles 
“Cadena Cuero, Calzado e Industria Marroquinera - DNP” Recuperado de:

https://colaboracion.dnp.gov.co/CDT/Desarrollo\%20Empresarial/Cueros.pdf

\section{Calzado en Bogotá}

En Bogotá en el barrio Restrepo funcionan unas 1.500 empresas de calzado, y cuenta con la marca "Hecho en el Restrepo", barrio considerado insignia de la industria del calzado y donde funciona el Museo del Cuero. La mayoría de pymes dedicadas a esta actividad, afrontan problemas financieros en todo el país, por la inundación de calzado asiático. En el Valle del Cauca trabajan unos 500 talleres de calzado, y en Cúcuta, Norte de Santander, destacan Mussi Zapatos, con más de 30 años de trayectoria y Calzado Gilvanni, que lleva 13 años produciendo calzado. En su conjunto el sector es uno de los más significativos de la industria colombiana, como que representa cerca del $1 \%$ de la producción y participa con más de $3 \%$ del empleo.

En Colombia el sector, agrupado en la Asociación Colombiana de Industriales del Calzado, el Cuero y sus Manufacturas, ACICAM, está constituido en un $98 \%$ por micro, pequeña y medianas empresas (MiPymes), tiene mucho camino por recorrer, y buenas perspectivas para exportar sus productos a EE.UU., Países Bajos, Brasil, Guatemala, Perú, Ecuador, Chile, Rusia, y el Triángulo Norte. A la Unión Europea el calzado colombiano llega con cero aranceles. Por su parte en Colombia desempacan maletas las cadenas de venta de calzado Luis Onofre, Calzados Marypaz y Tino González. Colombia, entre un grupo de cinco países, es el menor consumidor de ropa y zapatos, con siete unidades anuales en el 2012, señala la firma Euromonitor. 
Forero Medina, L. (2016, junio 27). Cuero, calzado y marroquinería, Sector de talla mundial. Radio Santafé. Recuperado de: http://www.radiosantafe.com/2016/06/27/cuerocalzado-y-marroquineria-sector-de-talla-mundial/

La industria de la moda colombiana ha iniciado el 2016 con muy buenos resultados. Todos los sectores comenzaron el año con cifras positivas y un aumento significativo en su producción. Tal es el caso de un 7,3 por ciento en confecciones y 8,7 \% en el gremio del calzado, donde la calidad sobresale en el uso de materiales y en los terminados. En el caso de Bogotá esta industria se mueve, sobre todo, en zonas populares, en donde talleres improvisados sirven para moldear toda clase de productos $\mathbf{y}$ en donde día a día se forjan cada vez más empresarios que lo único que necesitan es algo de apoyo para sobresalir.

Por esta razón, es que iniciativas como Bogotá Fashions Week se convierten en una plataforma para fortalecer las capacidades productivas y la oferta de moda en la ciudad de Bogotá, además de contribuir y posicionar al país como destino de moda y turismo, generando emprendimiento y negocios. Con estos escenarios los empresarios están promoviendo la consolidación internacional de la capital como referente de la industria de la moda en América Latina.

(2016, mayo 17). "Confección y calzado pasan por un buen momento en el país". El tiempo. Recuperado de: http://www.eltiempo.com/bogota/sector-de-la-confeccion-y-elcalzado-en-colombia/16594997

Por lo anterior se considera que el comportamiento del mercado del calzado en Bogotá ha tenido variaciones en los últimos años donde se vio afectado por la incursión del calzado asiático que era mucho más económico, pero de mala calidad, sin embargo, esto dio paso para que los comerciantes colombianos se fortalecieran y actualmente el sector es más 
atractivo para invertir por cuanto existen unas bases sólidas representadas en empresarios que buscan que el mercado crezca.

Según un artículo de la revista Portafolio publicado el 9 de febrero de 2017 el gobierno nacional en conjunto con los empresarios del sector calzado en Colombia, buscan a través de un plan integral que la productividad de más 600 empresas de calzado y cuero mejore, todo esto de la mano de los buenos resultados presentados por el sector el año pasado, representados en exportaciones por más de 179,8 millones de dólares, con una variación positiva del 3,6 cifra que no se veía desde 2012.

"El sector del calzado tuvo un aumento interesante, incluso por encima del total de la industria. Es decir que ha sido el cuarto rubro de mayor crecimiento en el año pasado, a cierre del mes de noviembre”, opinó al respecto Luis Gustavo Flórez, presidente de la Asociación Colombiana de Industriales del Calzado, Cuero y sus Manufacturas.

(2017, febrero 9) "Producción de calzado muestra un crecimiento importante" Portafolio

Recuperado de: http://www.portafolio.co/negocios/produccion-de-calzado-aumento-en$\underline{2017-503271}$

La Feria Internacional del Cuero, Calzado, Marroquinería, Insumos y Tecnología febrero 2017 fue todo un éxito y supero las expectativas en cuanto a resultados, donde se presentaron más de 500 empresas dando a conocer lo mejor del cuero, calzado y marroquinería y el énfasis fue la propuesta eco amigable.

"Más de 13 mil personas Visitaron la feria IFLS+EICI" Recuperado de: http://www.ifls.com.co/index.php?option=com_content $\& v i e w=\operatorname{article} \& i d=132$ 
Todo lo anterior evidencia que el sector del calzado está mejorando y se abre paso para ocupar un lugar importante en la producción del país, esto es positivo por cuanto asegura la supervivencia del negocio del calzado en Colombia.

\section{Futuro general del sector}

La expectativa de lo que suceda con el sector gira en torno al impacto de la reforma tributaria que, sin duda, tendrá su efecto en el consumo de los hogares, los cuales representan la mayor demanda de este tipo de productos, pues habrá menor disponibilidad de recursos para acceder a estos bienes.

Sin embargo, por otro lado, hay un aspecto importante y tiene que ver con la entrada en ejecución de las nuevas medidas adoptadas por el Gobierno a partir de noviembre del año pasado con los decretos 1744 y 1745 , que apuntan a neutralizar las importaciones a precios anormalmente bajos. Luis Gustavo Flórez, presidente de ACICAM, considera que la correcta aplicación de esas medidas puede marcar una ruta de crecimiento, puesto que ayudara a tener una competencia más sana y justa.

Para este año se espera que la producción de calzado crezca alrededor de $6 \%$, jalonada por la tasa de cambio, mayores pedidos por parte del sector oficial y por el efecto del control aduanero a las importaciones.

Así, paso a paso, esta industria se la juega para continuar aportándole al crecimiento de las regiones y las seccionales de ACICAM tendrán un papel determinante en ese propósito. 
(2017, febrero 16). “2017 Será complejo para la industria del cuero y el calzado en Colombia” Dinero.

Recuperado de: http://www.dinero.com/edicion-impresa/negocios/articulo/perspectivas-de$\underline{\text { la-industria-del-cuero-y-el-calzado-en-colombia/242008 }}$

El país mostro el último año un crecimiento positivo en términos de producción, "El sector del calzado tuvo un aumento interesante, incluso por encima del total de la industria. Es decir, ha sido el cuarto rubro de mayor crecimiento en el año pasado, a cierre del me de Noviembre" opinó Luis Gustavo Flórez, presidente de la Asociación Colombiana de Industriales del Calzado, Cuero y sus Manufacturas. Recuperado de: http://www.portafolio.co/negocios/produccion-de-calzado-aumento-en-2017-503271

Por lo anterior se considera que el camino a seguir es dar valor agregado a los productos esto es clave para lograr ofrecer diseños, tecnología, y mejores usos (funcionalidad). El propósito es marcar la diferencia para ser competitivos con los mercados internacionales.

También es importante para el sector el hecho de que se les coloque un freno a los precios bajos de las importaciones, ya que esto podría disminuir el ingreso de calzado extranjero y dará oportunidad a los locales.

Por otra parte, desde Pro export, el mensaje para el sector es trabajar en innovación de producto y conocimientos del mercado al que se quiere llegar, mejorar la calidad en el servicio y hacer seguimiento a los clientes.

Puntualmente para los exportadores de cuero y calzado, la estrategia de Pro export, está fundada en la búsqueda de oportunidades con el fin de que más empresas colombianas se 
conviertan en proveedoras de grandes marcas. Para ellas se han identificado canales de comercialización como boutiques especializadas, tiendas por departamentos, distribuidores y ventas por internet.

\section{Análisis económico sectorial. Análisis de la oferta. Cuantos - quienes - donde - que - como - Comparación}

En Chapinero se localiza el mayor número de empresas de Bogotá, 23.581, equivalente al 12\%. La estructura empresarial de la localidad se concentra en el sector servicios (84\%), industria $(5,9 \%)$ y construcción $(5,8 \%)$. En la localidad hay una alta presencia de microempresarios. Del total de empresas (23.581), 16.283 son microempresas que representaron el 69\% de la localidad y el 9,3\% de Bogotá.

En el 2004 se registraron 203 mil empresas en Bogotá. De éstas, 12\%, equivalentes a 23.581 empresas, se ubicaron en la localidad Chapinero. Frente a las demás localidades de la ciudad ocupó el primer lugar por número de empresas. En términos del valor de los activos, las empresas en Bogotá reportaron $\$ 320$ billones, de los cuales $\$ 130$ billones pertenecen a la localidad de Chapinero, por lo cual también se ubicó en el primer puesto con este indicador.

Úrsula Mena Lozano Tora (2008, noviembre) “Secretaria Distrital de Cultura, Recreación y Deportes, Vatorio de Culturas” Localidad de chapinero ficha Básica. Recuperado de: http://www.culturarecreacionydeporte.gov.co/observatorio/documentos/localidades/chapine $\underline{\text { ro.pdf }}$ 
Ilustración 3. Número de empresas ubicadas en Chapinero

\section{Tabla 11. Número de empresas ${ }^{28}$ ubicadas en Chapinero}

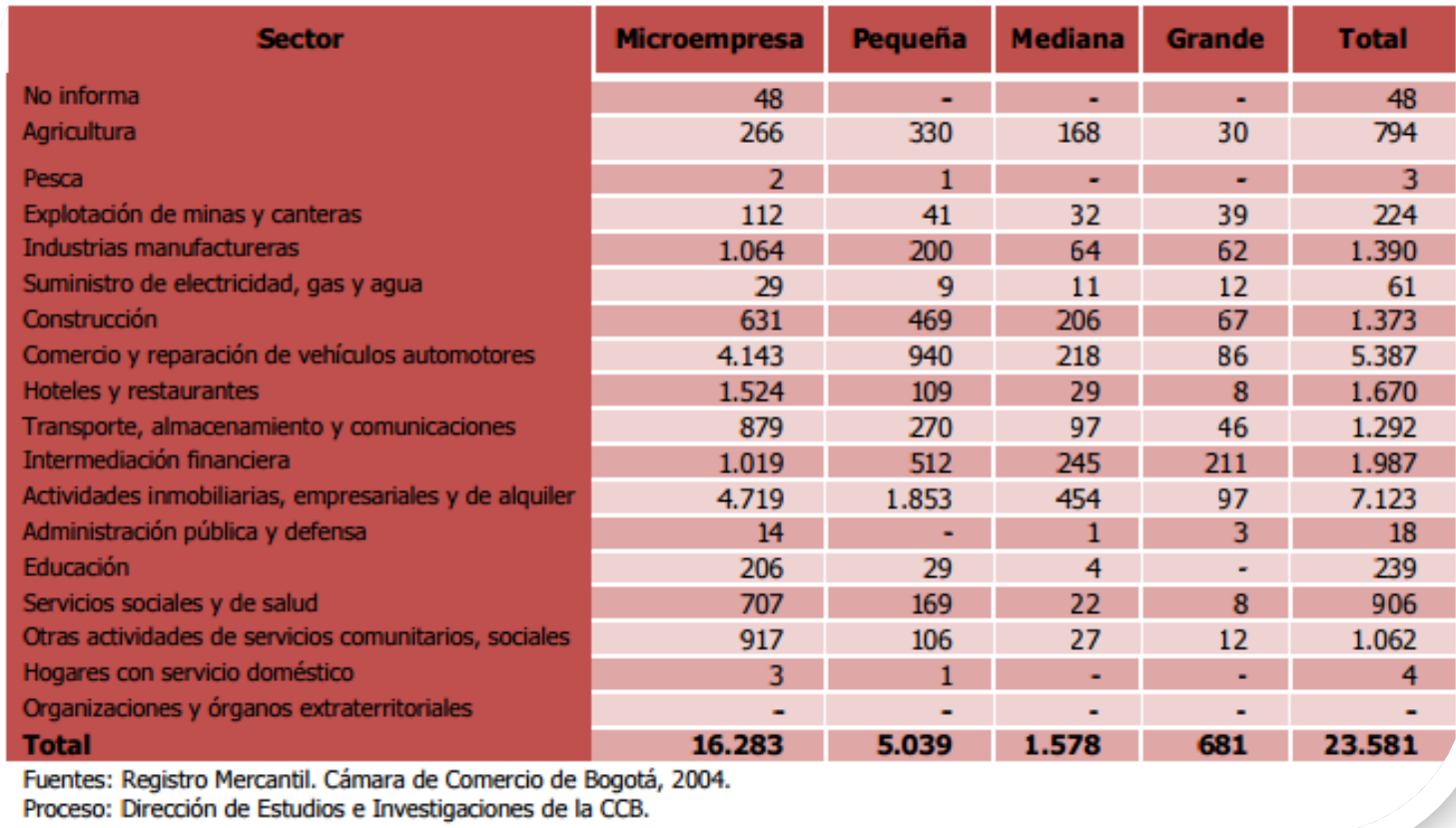

Úrsula Mena Lozano Tora (2008, noviembre) “Secretaria Distrital de Cultura, Recreación y

Deportes, Vatorio de Culturas" Localidad de chapinero ficha Básica. Recuperado de:

http://www.culturarecreacionydeporte.gov.co/observatorio/documentos/localidades/chapine

ro.pdf

Por lo anterior podemos concluir que el sector de chapinero es un sector comercial y empresarial, donde además de los comercios se encuentran 15 centros de educación superior como La Universidad Javeriana, La Universidad Santo Tomás, La Universidad de la Salle, La Católica, entre otras, que hacen de la localidad un lugar donde concurren gran cantidad de personas y esto favorece el comercio, es por ello que en las diferentes 
festividades del año como Halloween, día de enamorados y especialmente navidad, las calles de chapinero se convierten en almacenes ambulantes donde comerciantes venden sus mercancías.

Ahora bien para el calzado no es diferente, en este sector se encuentran desde marcas muy reconocidas a nivel nacional como Bosi, Bata, Vélez, Spring Step, Calzado Bucaramanga, hasta almacenes conocidos solo a nivel local como Calzado tonino, Caprino, Smith Shoes, entre otros, según la página Cívico Bogotá la cual muestra ubicación de almacenes recomendados de calzado, para la localidad de chapinero arroja 290 resultados, lo que quiere decir que existen 290 locales dedicados a esta actividad.

\section{Análisis de la demanda - social - demográfica - económica y cultural}

Por número de habitantes, Chapinero es la quinta localidad más pequeña; según el Censo de 2005 ocupa la posición 15, con 122.089 personas, un 1,80\% del total de la Ciudad. Por sexo, el $55 \%$ constituida por mujeres y el $45 \%$ por hombres. Por rango de edad, el $60 \%$ de su población está entre los 15 y los 55 años.

Jefe de hogar: De 50.351 hogares, en 31.362(62,3) el jefe de hogar es hombre y en 18.989(37,7\%) es mujer, de los cuales $17.478(92 \%)$ no tienen cónyuge y en $2.565(13,5)$ de esos hogares hay hijos menores de 18 años.

Úrsula Mena Lozano Tora (2008, noviembre) “Secretaria Distrital de Cultura, Recreación y Deportes, Vatorio de Culturas” Localidad de chapinero ficha Básica. Recuperado de: http://www.culturarecreacionydeporte.gov.co/observatorio/documentos/localidades/chapine $\underline{\text { ro.pdf }}$ 


\section{rinda}

Al sector de chapinero no se le puede definir una identidad propia esto debido a que al ser centro de la actividad financiera, comercial y de servicios de Bogotá, se mezcla lo antiguo de los primeros barrios con la modernidad de los nuevos y modernos edificios, un ejemplo de ello es el Edificio Doctor Angélico ubicado en la Cra. 9 n 72- 90 un edificio inteligente y moderno de la Universidad Santo Tomás, cuya inauguración se realizó el 5 de agosto de 2013, que tiene cerca el colegio Gimnasio Moderno de Bogotá ubicado en la Cra. 9 n 7499 construido en 1914.

Ilustración 4.Edificios de Chapinero
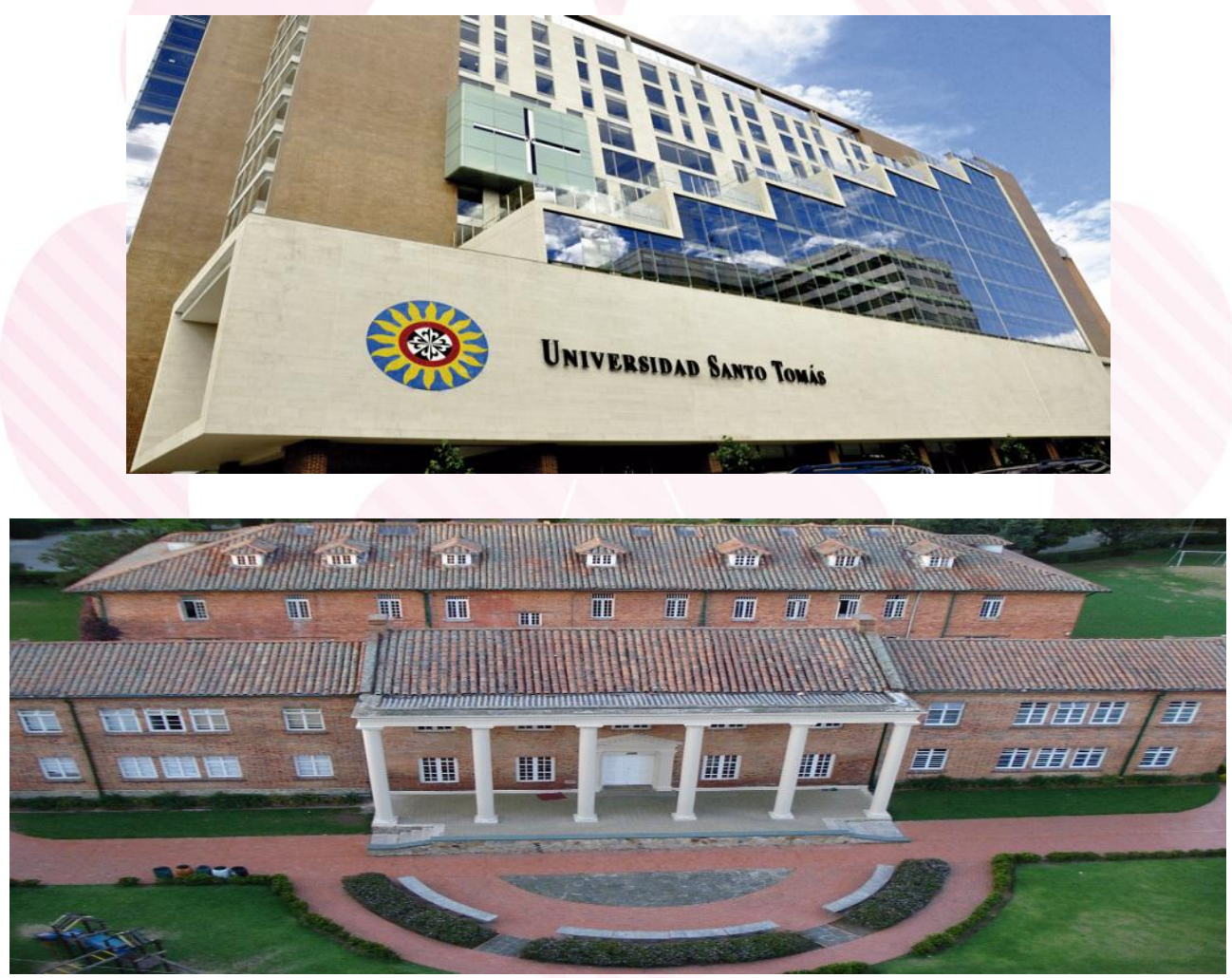

Imágenes Tomadas de: https://www.google.com.co/search

Como se menciona anteriormente el sector cuenta con 15 instituciones de educación superior lo que trae personas de otras localidades además de las propias, así las cosas, las noches en chapinero son muy activas dando apertura a bares de rumbas de diferentes 
culturas nacionales como internacionales, y se realizan actividades culturales de tipo artístico como teatro, pintura, baile etc.

Según la ficha básica de chapinero por la presencia de las universidades y negocios la población flotante quintuplica a la población residente de chapinero. Úrsula Mena Lozano Tora (2008, noviembre), esto se puede aprovechar como oportunidad para el negocio en razón de que el mercado es grande.

En este sector se encuentran diferentes tipos de personas y estratos, ejecutivos, vendedores ambulantes, amas de casa, estudiantes, lustrabotas, comerciantes, etc. y confluyen diferentes culturas costeños, chocoanos, paisas, extranjeros, entre otros.

\section{PRESENTACION DE RESULTADOS}

Para realizar la investigación de mercados con el fin de establecer si los zapatos serian atractivos o no para el mercado objetivo, y establecer aspectos como materiales, frecuencia de compra e inversión de compra, se aplicó el siguiente formato de encuesta a mujeres mayores de los 15 años en el sector de Chapinero de la ciudad de Bogotá. 
Ilustración 5. Encuesta zapatos Luzinda

\section{ENCUESTA ZAPATOS LUZINDA}

Por favor realice esta encuesta, la cual nos proporcionara la información pertinente al lanzamiento de los zapatos LUZINDA al mercado.

*Obligatorio

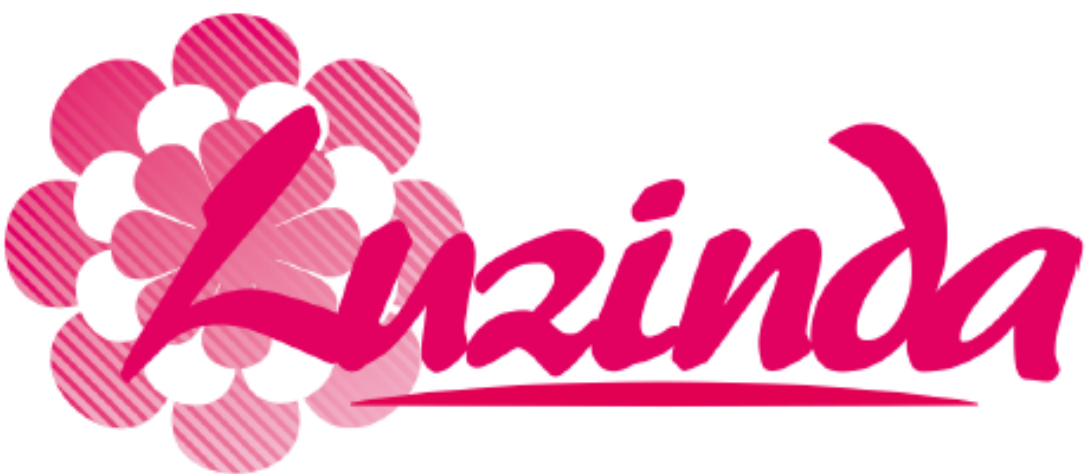

1. NOMBRE *

2. EDAD

3. ESTRATO *

Marca solo un óvalo.

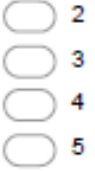

4. NIVEL EDUCATIVO

Marca solo un óvalo.
ESTUDIANTE
BACHILLER
TECNICO O TECNOLOGO
UNIVERSITARIO
Otros: 


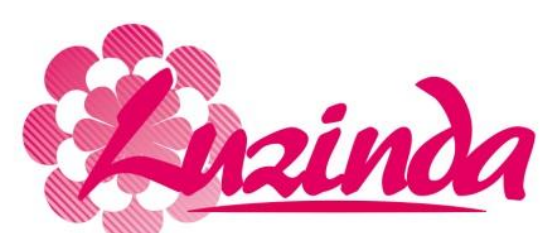

5. ¿En cual de las siguientes redes sociales, habitualmente conoce usted de productos nuevos en el mercado? *

Marca solo un óvalo.

$\square$ INSTAGRAM
$\square$ FaceboOK
$\square$ You tube
$\square$ Otros:

6. ¿Con que frecuencia compra zapatos? *

Marca solo un óvalo.

DE 2 A 3 MESES

DE 3 A 6 MESES

DE 7 A 12 MESES

Otros:

7. ¿Cuanto dinero invierte usted para la compra de un par de zapatos? * Marca solo un óvalo.

DE $\$ 80.000$ A $\$ 100.000$

DE $\$ 100.000$ A $\$ 130.000$

DE $\$ 130.000 \mathrm{~A} \$ 180.000$

Otros:

8. ¿Que factor resulta predominante para usted a la hora de comprar zapatos? * Marca solo un óvalo.
CALIDAD
PRECIO
MARCA
Otros:

9. ¿Son de su agrado los zapatos de tacón corrido? Marca solo un óvalo.
Si
No
Tal vez

10. Que material es de su preferencia: Marca solo un óvalo.
CUERO
GAMUZA
SINTETICOS
Otros: 
11. ¿Compraría usted un Zapato con bolsillo secreto de seguridad para guardar efectivo y joyas?

Marca solo un óvalo.

Sí
No

12. ¿Considera usted que el producto mencionado en la pregunta anterior le genera mayor seguridad para llevar ciertos objetos de valor? *

Marca solo un óvalo.
Sí
( No

Fuente: Autoras

Dado que la población de mujeres mayores de 15 años del sector de Chapinero es de

65.600, la muestra que se tomó para el desarrollo de la encuesta fue de 96 mujeres,

esta muestra representativa se calculó a través de la calculadora muestra,

encontradas por internet y arrojan un nivel de confianza del $95 \%$.

Ilustración 6. Resultado calculadora muestral

http://www.corporacionaem.com/tools/calc_muestras.php 
Ilustración 7 Resultado calculadora muestral 2

\begin{tabular}{|c|c|c|}
\hline netquest & Soluciones & Contacto \\
\hline \multirow{2}{*}{$\begin{array}{l}\text { Calculadora de muestra para } \\
\text { proporciones }\end{array}$} & 65600 & 50 \\
\hline & TAMAÑO DEL UNIVERSO & HETEROGENEIDAD \% \\
\hline \multirow{2}{*}{$\begin{array}{l}\text { Calcula el tamaño de muestra que necesitas cuando tu encuesta mide un } \\
\text { porcentaje o proporción (por ejemplo, el \% de personas que fuman en la } \\
\text { población). En esta calculadora avanzada podrás ver cómo se relacionan } \\
\text { margen de error, nivel de confianza y tamaño de muestra. Más información } \\
\text { sobre las fórmulas empleadas aquí. }\end{array}$} & $\begin{array}{l}\text { Número de personas que } \\
\text { componen la población a }\end{array}$ & $\begin{array}{l}\text { Es la diversidad del universo. } \\
\text { Lo habitual es usar } 50 \% \text {, el }\end{array}$ \\
\hline & MARGEN DE ERROR \% & NIVEL DE CONFIANZA \% \\
\hline $\begin{array}{l}\text { Para usar la calculadora: } \\
\text { - Indica el tamaño del universo y qué grado de heterogeneidad hay en la } \\
\text { población. } \\
\text { - Indica } 2 \text { de los } 3 \text { parámetros restantes. Por ejemplo, si indicas la muestra } \\
\text { y el nivel de confianza, podrás calcular el margen de error. } \\
\text { - Pulsa en CALCULAR. El valor calculado quedará destacado. }\end{array}$ & $\begin{array}{l}\text { Menor margen de error } \\
\text { requiere mayor muestra. } \\
96 \\
\text { MUESTRA } \\
\text { Personas a encuestar }\end{array}$ & $\begin{array}{l}\text { Mayor nivel de confianza } \\
\text { requiere mayor muestra. Lo } \\
\text { habitual es entre } 95 \% \text { y } 99 \%\end{array}$ \\
\hline
\end{tabular}

https://www.netquest.com/es/panel/calculadora-muestras/calculadoras-estadisticas

Los resultados arrojados, fueron fundamentales para determinar aspectos del proyecto tal como las herramientas en internet que pueden impulsar el producto, para conocer el monto que las mujeres mayores de 15 años están dispuestas a invertir en la compra de un par de zapatos, conocer la frecuencia con que estas mujeres realizan compra de zapatos y cuáles son los factores predominantes a la hora de realizar esta compra, por otro lado y muy importante, si estas mujeres comprarían un zapato con las características de Luzinda.

Ilustración 8. Resultados encuesta - Estrato Socio Económico

Imagen 4. Resultados: Estrato

\section{ESTRATO}

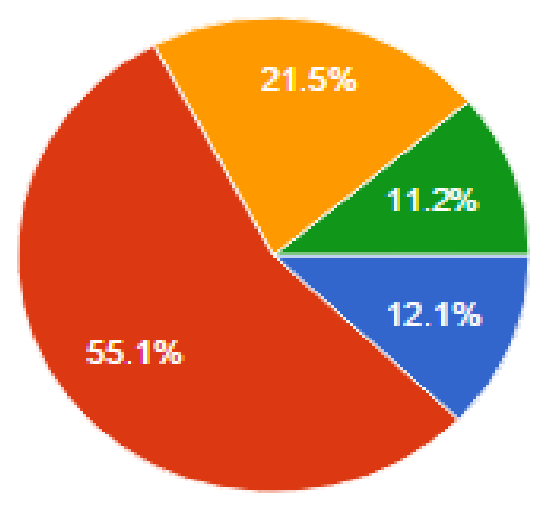

Fuente: Autoras 
Como se observa en la imagen 4 más del $50 \%$ de las mujeres que diligenciaron la encuesta

en el sector de Chapinero son estrato 3, con un $55.1 \%$

Ilustración 9. Resultados encuesta - Nivel escolaridad
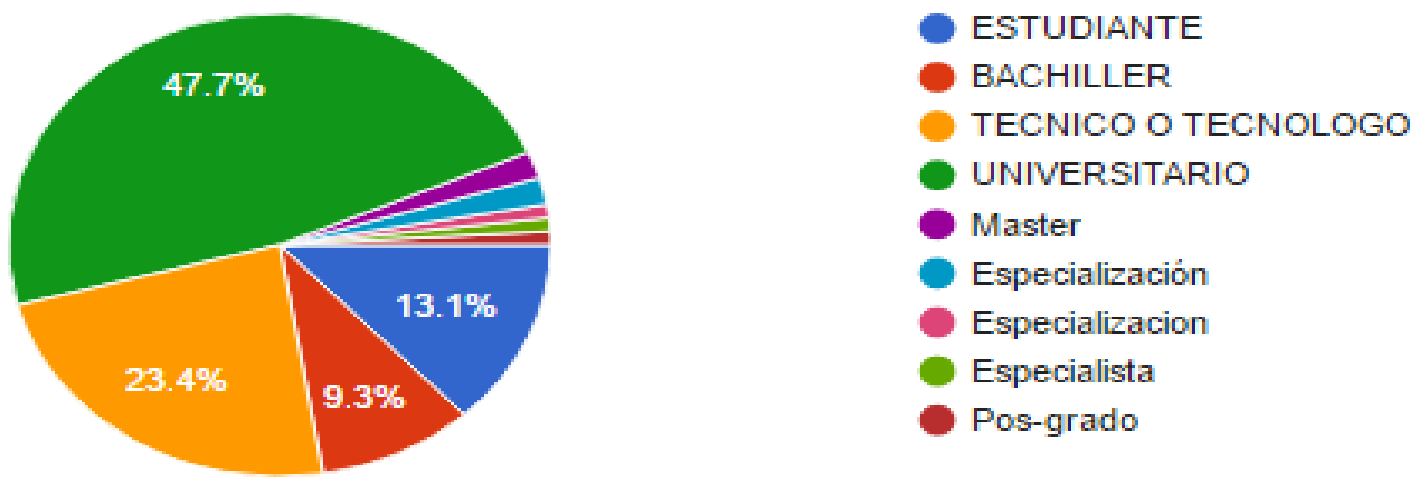

NIVEL DE ESCOLARIDAD

Fuente: Autoras

Ilustración 10. Resultados encuesta - Redes sociales

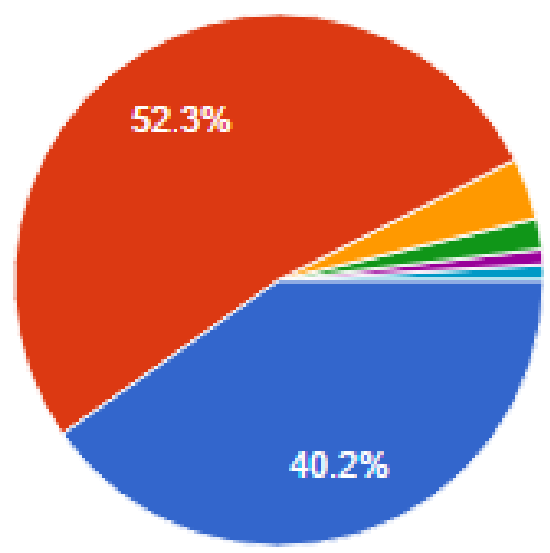

INSTAGRAM

FACEBOOK

YOU TUBE

Pinteres

Publicidad internet

No usa

RED SOCIAL EN LA QUE HABITUALMENTE CONOCEN DE PRODUCTOS

NUEVOS

Fuente: Autoras 
Como puede observarse en la imagen 6 , el $52.3 \%$ de las mujeres conoce de productos nuevos por la red social Facebook, seguidos por Instagram con un 40.2\%, siendo estas dos las redes sociales por las que más se dan a conocer productos nuevos en el mercado, acorde a las mujeres encuestadas.

Ilustración 11. Resultados encuesta - Frecuencia de compra

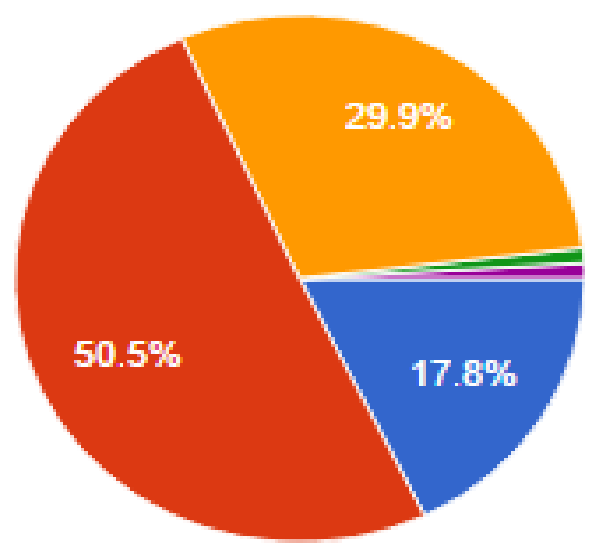

DE 2 A 3 MESES

- DE 3 A 6 MESES

DE 7 A 12 MESES

- Cada año

- 1 vez al mes

\section{FRECUENCIA DE COMPRA}

Fuente: Autoras

Como se observa en la imagen 7, el $17.8 \%$ de las mujeres compra zapatos cada 2 o 3 meses y el $50.5 \%$ de las mujeres con una frecuencia de 3 a 6 meses, lo cual es favorable para los zapatos Luzinda dado las mujeres compran con bastante regularidad un nuevo par de zapatos. 
Ilustración 12. Resultados encuesta - Dinero a invertir

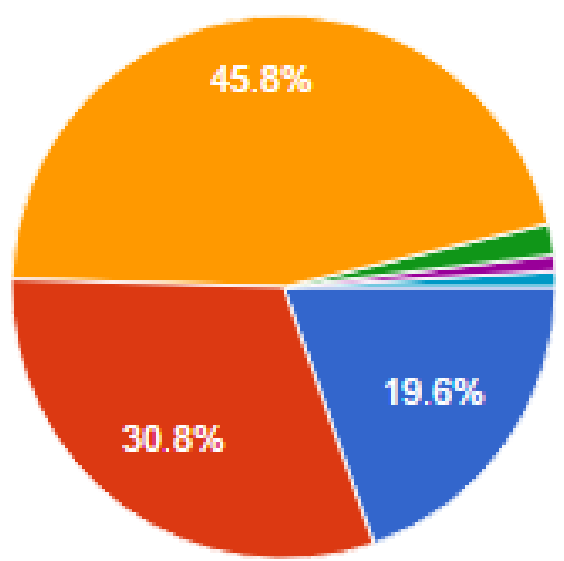

DE $\$ 80.000$ A $\$ 100.000$

DE $\$ 100.000$ A $\$ 130.000$

DE $\$ 130.000$ A $\$ 180.000$

200000

200.000

Más de $\$ 200000$

\section{DINERO INVERTIDO A LA HORA DE COMPRAR ZAPATOS}

Fuente: Autoras

Se observa según la imagen 8 , que el $45.8 \%$ de las mujeres encuestadas invierte entre $\$ 130.000$ y $\$ 180.000$ en un nuevo par de zapatos, seguido por un $30.8 \%$ que invierte entre $\$ 100.000$ y $\$ 130.000$, y nos indican los topes de precios en los cuales se pueden vender los zapatos Luzinda.

Ilustración 13. Resultados encuesta - factores predominantes a la hora de comprar

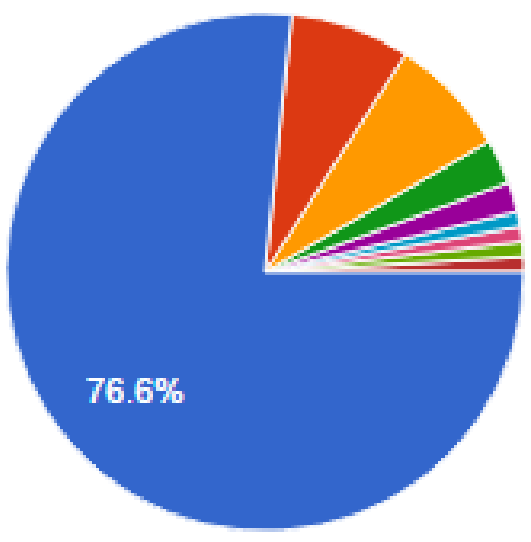
CALIDAD
PRECIO
MARCA
Modelo
Comodidad
Diseño
Que sean bonitos
Modelo o estilo
Diseño

\section{FACTOR PREDOMINANTE A LA HORA DE COMPRAR ZAPATOS}


Fuente: Autoras

Se puede observar que el factor que predomina a la hora de decidirse por unos zapatos, antes que el factor del precio o la marca, el 76.6\% de las mujeres encuestadas consideran que el aspecto más importante es la calidad, por tanto, Luzinda debe ser un zapato de alta calidad para satisfacer a sus clientes.

Ilustración 14. Resultados encuesta - Agrado por los zapatos de tacón corrido
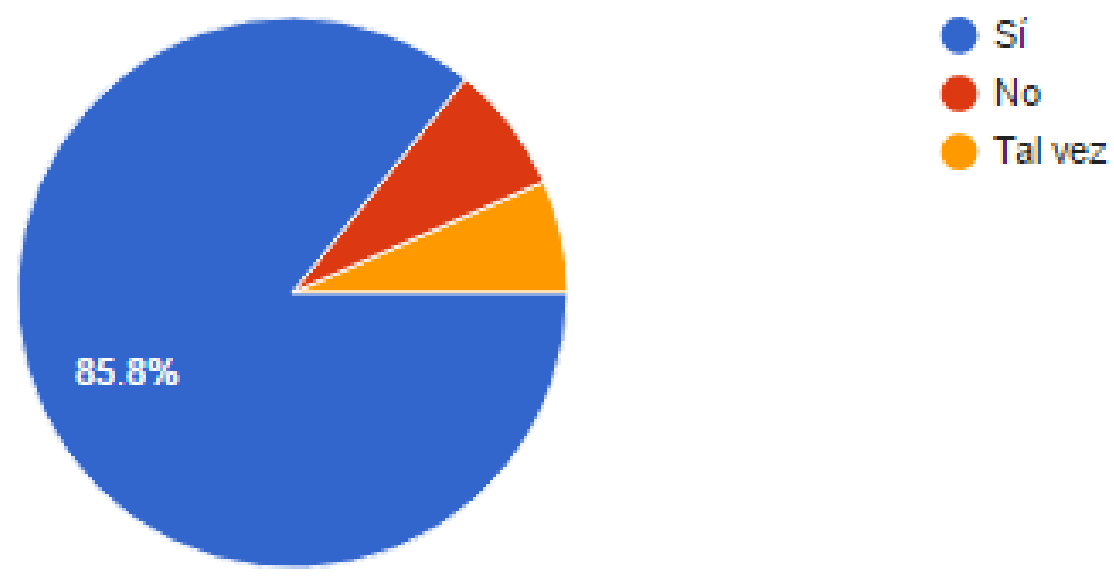

\section{AGRADO POR LOS ZAPATOS DE TACÒN CORRIDO}

Fuente: Autoras

Ilustración 15. Resultados encuesta - Materiales de preferencia
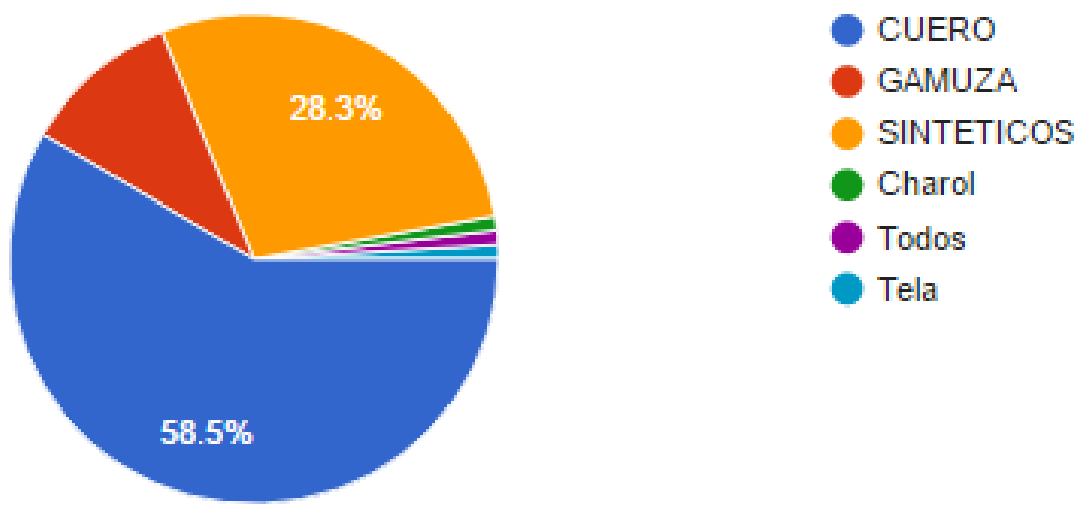

MATERIAL DE PREFERENCIA 
Fuente: Autoras

Ilustración 16. Resultados encuesta - Mujeres que comprarían el producto
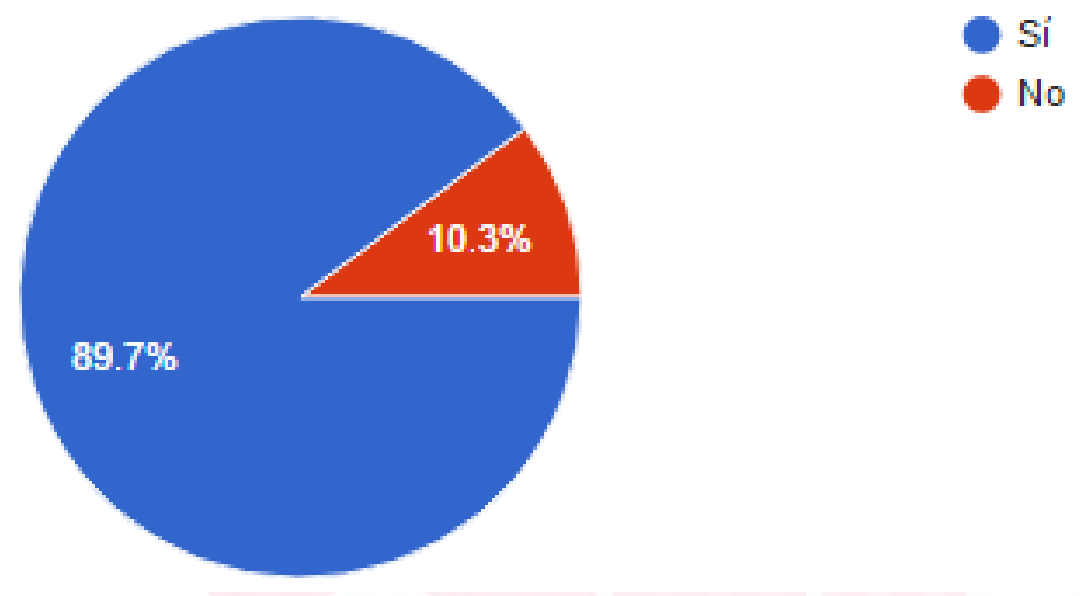

\% DE MUJERES QUE COMPRARÍA UN ZAPATO CON BOLSILLO SECRETO

Fuente: Autoras

Ilustración 17. Resultados encuesta - Seguridad que genera el producto

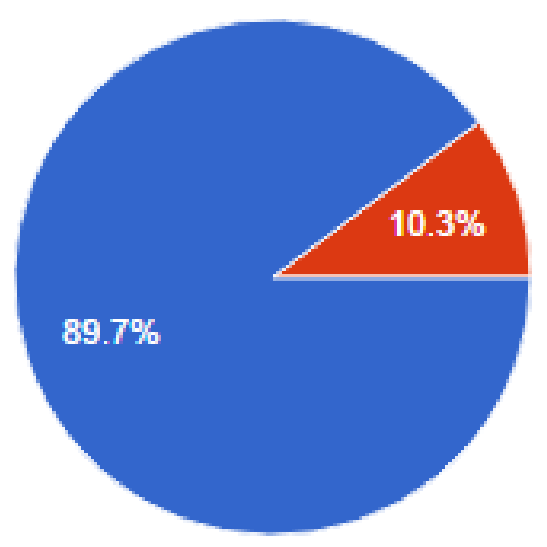

Si

EL ZAPATO LE GENERA SEGURIDAD PARA LLEVAR EN ÉL OBJETOS DE VALOR

Fuente: Autoras 
Como se observa en las imágenes 14 y 15, las mujeres encuestadas comprarían los zapatos Luzinda, un $89.7 \%$ indica que, si compraría un zapato que cuente con un bolsillo secreto, ya que le genera seguridad para transportar objetos pequeños de valor, lo cual indica aceptación del producto dentro de la muestra encuestada.

De la información arrojada por la encuesta se han decidido aspectos como la red social en la que más se debe publicitar el producto, la muestra indica con un 52.3\% que es Facebook, seguido por Instagram con un $40.2 \%$.

Por otro lado, se puede observar, que a la hora de comprar es predominante la calidad del producto y no la marca, por lo que Luzinda se caracteriza en ser un producto confortable y de calidad para su usuaria.

Se puede igualmente observar que más de la mitad de la muestra realiza compras de zapatos con una frecuencia de 3 a 6 meses invirtiendo en ello de $\$ 130.000$ a $\$ 180.000$ pesos, lo cual es un buen índice para Luzinda dado que esto puede verse representado en compras frecuentes a un precio favorable.

Con las últimas dos preguntas se observa que el producto tiene aceptación para la población de la cual fue tomada la muestra, soportado en que un $89.7 \%$ de mujeres compraría los zapatos Luzinda. 


\section{PERFIL DEL CLIENTE}

El mercado objetivo del producto son mujeres que tengan una edad superior a 15 años, que deben desplazarse en el transporte público y/o necesitan sentir seguridad de trasladar objetos como joyas o dinero, además que guste estar a la moda e innovar día a día en sus accesorios, en este caso los zapatos, que representa para la mujer un artículo indispensable a la hora de estructurar su vestuario del día a día.

Respecto a los factores económicos el prototipo es un producto que pueden adquirir mujeres que cuenten con ingresos mensuales desde un SMLV, inicialmente que estas mujeres estén ubicadas, en la cuidad de Bogotá en la localidad de Chapinero, ya que uno de los valores agregados para ofrecer a sus clientes es que puedan realizar sus compras de manera on-line por medio de la página web, debido a que en la actualidad muchas mujeres no cuentan con el tiempo para ir a un centro comercial a realizar sus compras, la compra on-line facilitara dicho proceso.

Se evidencia que en el rol que la mujer desempeña en la actualidad, necesita de herramientas que hagan más fácil su día a día, en su labor de profesionales, estudiantes y amas de casa, por lo que se encuentra que el producto satisface una necesidad en las mujeres en uno de los accesorios más importantes de su vestuario, los zapatos. 


\section{SEGMENTACIÓN DEL CLIENTE}

En Bogotá para el año 2017 se evidencia que la proyección de la población es de

8.080.734 del cual el 4.167.824 son mujeres, de estas (3.285.205) son mujeres mayores de

15 años de edad.

Según la secretaria distrital de planeación la proyección de población del sexo femenino desde el año 2016 al 2020, es la siguiente:

Ilustración 18. Proyecciones de población Mujeres 2018

\begin{tabular}{|c|c|c|c|c|c|}
\hline & 2016 & 2017 & 2018 & 2019 & 2020 \\
\hline Localidad & Mujeres & Mujeres & Mujeres & Mujeres & Mujeres \\
\hline USAQUÉN & 253.449 & 253.926 & 254.310 & 254.608 & 254.841 \\
\hline CHAPINERO & 66.449 & 66.033 & 65.600 & 65.158 & 64.711 \\
\hline SANTA FE & 47.832 & 47.135 & 46.438 & 45.727 & 45.019 \\
\hline SAN CRISTÓBAL & 203.869 & 202.823 & 201.727 & 200.567 & 199.363 \\
\hline USME & 172.215 & 173.754 & 175.249 & 176.700 & 178.104 \\
\hline TUNJUELITO & 95.683 & 94.819 & 93.941 & 93.048 & 92.144 \\
\hline BOSA & 363.363 & 374.723 & 386.336 & 398.177 & 410.260 \\
\hline KENNEDY & 608.338 & 619.048 & 629.715 & 640.355 & 650.969 \\
\hline FONTIBÓN & 213.035 & 218.479 & 223.980 & 229.543 & 235.174 \\
\hline ENGATIVÁ & 453.981 & 456.270 & 458.421 & 460.416 & 462.301 \\
\hline SUBA & 655.579 & 671.998 & 688.551 & 705.323 & 722.299 \\
\hline BARRIOS UNIDOS & 131.616 & 132.736 & 133.823 & 134.893 & 135.929 \\
\hline TEUSAQUILLO & 74.145 & 73.810 & 73.454 & 73.092 & 72.718 \\
\hline LOS MÁRTIRES & 46.543 & 46.240 & 45.901 & 45.566 & 45.219 \\
\hline ANTONIO NARINIO & 55.664 & 55.552 & 55.427 & 55.281 & 55.133 \\
\hline PUENTE ARANDA & 113.322 & 111.422 & 109.526 & 107.629 & 105.742 \\
\hline LA CANDELARIA & 10.516 & 10.393 & 10.270 & 10.150 & 10.021 \\
\hline RAFAEL URIBE URIBE & 180.846 & 179.322 & 177.753 & 176.132 & 174.494 \\
\hline CIUDAD BOLÍVAR & 368.367 & 375.711 & 383.066 & 390.452 & 397.847 \\
\hline SUMAPAZ & 3.565 & $\mathbf{3 . 6 3 0}$ & 3.706 & 3.772 & 3.844 \\
\hline TOTAL BOGOTÁ & 4.118.377 & 4.167.824 & 4.217.194 & 4.266 .589 & 4.316.132 \\
\hline
\end{tabular}

Fuente: DANE

Tomado:http://www.sdp.gov.co/PortalSDP/InformacionTomaDecisiones/Estadisticas/Proye

$\underline{\text { ccionPoblacion }}$ 
Como parte de la investigación se encuentra: En una encuesta realizada por Fenalco sobre el consumo en Colombia, la marca no es determinante al momento de la compra en cuanto a zapatos y ropa se refiere, se toman estas dos últimas variables ya que están íntimamente relacionados con el producto, mostrando el comportamiento del mercado objetivo. La encuesta arroja que un $85 \%$ de los encuestados se preocupa por el material en cuanto calzado y en ropa un $80 \%$ a la calidad.

“Calidad del producto determina la decisión de compra de los colombianos” Recuperado de: http://www.fenalco.com.co/node/4720

\section{PLAN DE MERCADEO}

\section{Estrategias de distribución:}

Basados en los resultados de la muestra se determina que las redes sociales más empleadas para conocer de un producto son Facebook con un 52.3\%, seguida de Instagram con el 40,2\%, por lo cual estos serán los medios por los cuales se dará a conocer los zapatos

\section{Luzinda.}

Luzinda, contará con un punto de venta en el sector de Chapinero, allí los clientes podrán realizar su compra, por otro lado, se emplearán redes sociales como Instagram y Facebook, debido a que son los medios más utilizados por las personas para interactuar y conocer productos, por este medio los clientes podrán hacer sus pedidos, para realizar la entrega el medio a utilizar será empresas de mensajería donde el cliente asumirá el costo de envió. 


\section{Publicidad:}

Inicialmente toda la publicidad será manejada por las redes sociales, creando videos y subiendo fotos del producto, interactuando con los clientes, así como también a través de la página web de la marca.

Adicionalmente se van a utilizar herramientas publicitarias como pendones los cuales se exhibirán cuatro veces al año y volantes publicitarios dos veces al año, los cuales se modificarán cada semestre en ocasión de las fechas especiales celebradas en Colombia, Día de las madres, Amor y Amistad y Navidad.

\section{Estrategias de comunicación:}

La comunicación se realizará de manera constante en las redes sociales, apoyados en la frase “Luce Linda y segura con Luzinda” se buscará crear recordación de la marca.

En la página web https://zapatosluzinda.wixsite.com/luzinda, existirá un link de contactos en el cual los clientes podrán comunicar sus inquietudes o sugerencias respecto al producto, también podrán hacerlo por el correo zapatosluzinda@ hotmail.com.

\section{Fidelización:}

Como estrategia de fidelización se creará un producto de calidad, con diseños innovadores ya la vanguardia, que sean atractivos para los clientes, el servicio es primordial para hacer la diferencia y captar la atención de los clientes. 


\section{Postventa - servicio al cliente:}

El servicio postventa y servicio al cliente, se basará en la creación de una base de datos con información como correos electrónicos y números de teléfono celular, para enviar a estos la información de promociones y nuevos diseños.

\section{ESTUDIO DE OPERACIONES}

\section{Descripción del proceso de fabricación}

1. Modelaje - proceso en el cual el modelador realiza un molde acorde al diseño del zapato, lo entrega en una lámina que permite el óptimo corte de material del cual estará hecho el zapato, por lo general se inicia por la horma 6, para de allí escalar a las otras tallas bien sea hacia abajo o hacia arriba.

2. Cortar el cuero para el empeine, talones, laterales, punteras y tacones de los zapatos, con un escalpelo o un bisturí, esto siguiendo los patrones del diseño. Se debe tener en cuenta que al cortar e deben dejar por lo menos $2.5 \mathrm{~cm}$ de cuero adicional a lo largo del borde inferior del zapato, al igual que dejar un centímetro aproximadamente en los lugares donde las piezas superiores se unen ya que esto dará el margen de la costura.

3. Guarnición y costura, proceso en el cual se unen las piezas de cuero y/o material sintético y textiles, para formar el corte a través de la costura y los pegantes.

4. Solador o montaje - Ajustar con tachuelas las punteras y los laterales sobre la horma. Sujetar con tachuelas el cuero del tacón en su sitio, alrededor de los tacones. Estirar y tensar las piezas de cuero con las pinzas, después de tener el montaje se raspan y cortan los sobrantes. 
5. Remojar las hormas en agua tibia hasta que el cuero esté saturado.

6. Dejar que el cuero se seque sobre las hormas y los tacones, se ponen ojales.

7. Pegar la suela, dejar un tiempo para que se solidifiquen, para lo que se emplean 2 tipos de pegantes y se aplica un activador que permite que el pegante se esparza adecuadamente por toda la superficie lo que permite que el zapato pegue bien.

8. Después se llevan al horno donde se perfecciona el pegue del zapato donde actúa el activador.

9. Recortar los excedentes del cuero y de la suela.

10. Forrar los zapatos con una plantilla.

11. Impermeabilizar con un sellador en aerosol, con el fin de evitar que le ingrese el agua.

12. Finizaje: proceso en el que se maquillan los zapatos, se introduce la plantilla, se ponen los cordones, en el caso de zapatos de charol se emplea crema de manos para que el zapato quede brillante, y se agregan accesorios decorativos.

13. Empaque. 


\section{DIAGRAMA DE FLUJO}

Ilustración 19. Diagrama de flujo

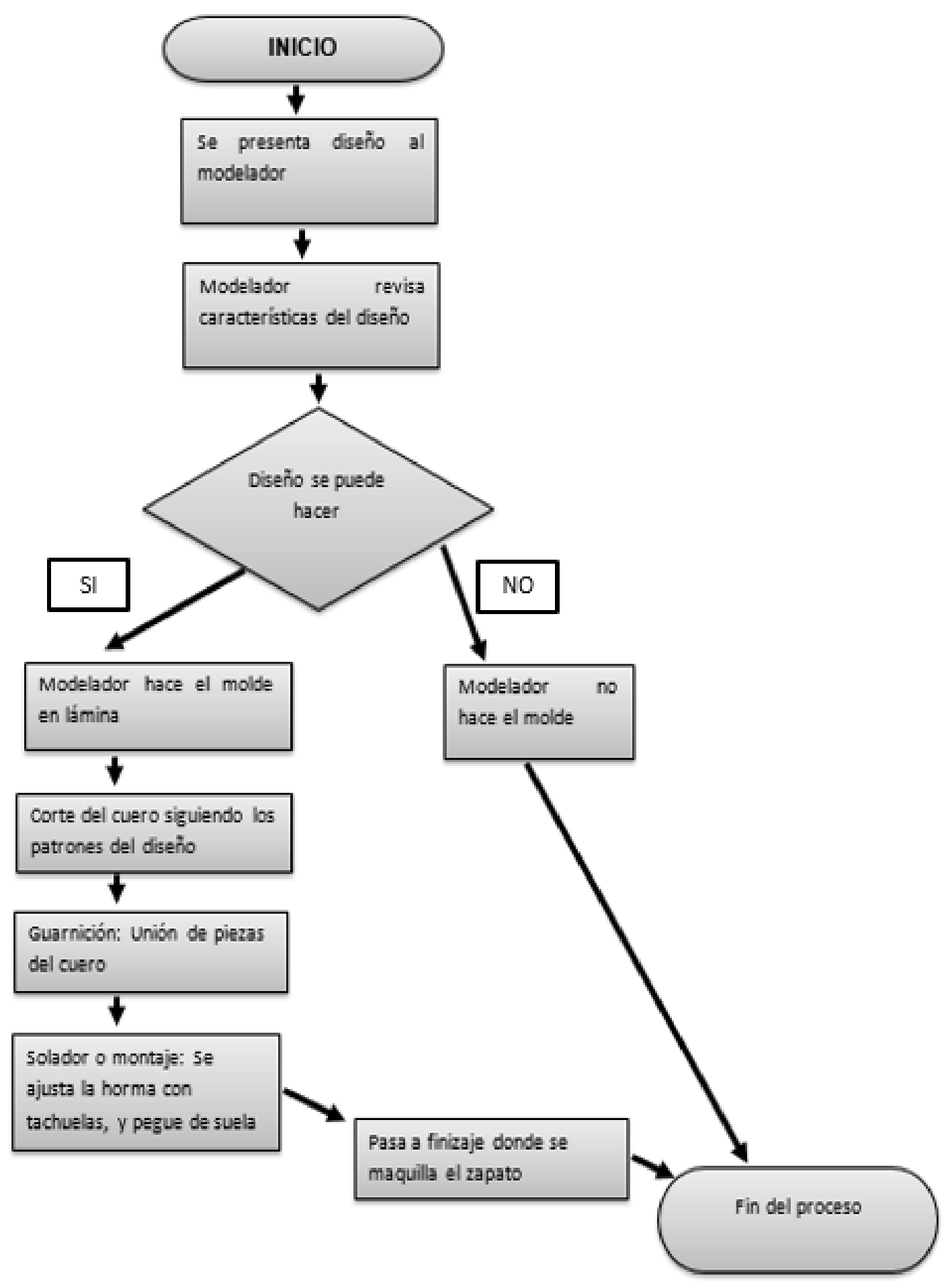

Fuente: Autoras 


\section{Inversión en infraestructura}

Luzinda SAS, contará con un espacio físico ubicado en el sector de Chapinero de Bogotá, el cual se compone de un espacio para la operación de la planta, un espacio de oficina propicio para las labores administrativas y comerciales de la empresa y un espacio de local comercial en el primer nivel.

El canon de arriendo que se paga por concepto de arriendo incluye el espacio de planta, oficinas y local.

\section{Ilustración 20. Distribución de planta}

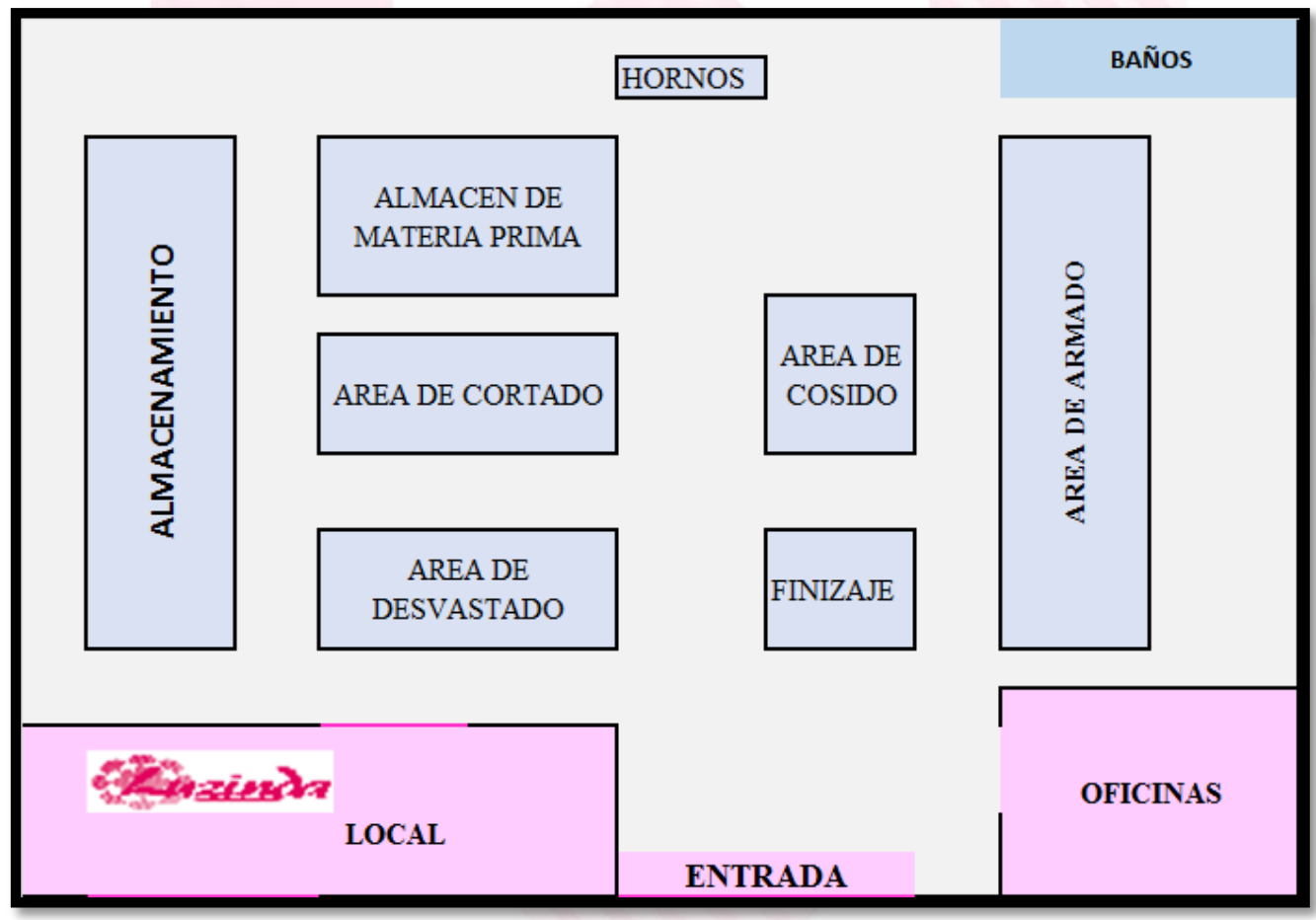

Fuente: Autoras 


\section{Inversión en capital de trabajo}

Luzinda SAS, realizará la inversión que se relaciona a continuación con el fin de dar inicio a las operaciones de la empresa, tanto las maquinas necesarias para el proceso de fabricación como los equipos de oficina necesarios para el desarrollo de las labores administrativas.

Ilustración 21. Inversión en equipos

\begin{tabular}{|c|c|c|c|}
\hline \multicolumn{4}{|c|}{ EQUIPOS DE OFICINA } \\
\hline CANTIDAD & CONCEPTO & & ALOR \\
\hline 2 & Escritorios & $\$$ & 498.000 \\
\hline 4 & Sillas & $\$$ & 405.000 \\
\hline 1 & Archivador & $\$$ & 329.000 \\
\hline 2 & Equipos de computo & $\$$ & 2.100 .000 \\
\hline 1 & Impresora multifuncional & $\$$ & 400.000 \\
\hline 1 & Telefono & $\$$ & 45.000 \\
\hline & SUBTOTAL & $\$$ & 3.777 .000 \\
\hline \multicolumn{4}{|c|}{ EQUIPOS DE PRODUCCION } \\
\hline CANTIDAD & CONCEPTO & & ALOR \\
\hline 1 & Mesa de corte & $\$$ & 500.000 \\
\hline 1 & guarnecedora & $\$$ & 650.000 \\
\hline 1 & Horno reactivador & $\$$ & 5.000 .000 \\
\hline 4 & Estanteria metalica & $\$$ & 1.139 .600 \\
\hline 1 & Troqueladora & $\$$ & 5.500 .000 \\
\hline \multicolumn{2}{|r|}{ SUBTOTAL } & $\$$ & 12.789 .600 \\
\hline \multicolumn{2}{|r|}{ TOTAL } & $\$$ & 16.566 .600 \\
\hline
\end{tabular}

Fuente: Autoras 


\section{Costos de mano de obra}

A continuacion se relacionan los costos de mano de obra de los operarios de Luzinda SAS, igualmente los costos de nomina administrativos de los cargos que requiere la empresa para su funcionamiento, teniendo en cuenta las provisiones que de carácter mensual se deben tener en cuenta:

Ilustración 22. Nómina operarios

\begin{tabular}{|c|c|c|c|c|c|c|c|c|c|c|c|c|c|c|c|c|c|c|}
\hline & & & & & & & & & OYFCC & CION NOMII & IA OPERARIC & & & & & & & \\
\hline CONCEPTO & $\%$ & MES 1 & MES 2 & MES 3 & MES 4 & MES 5 & MES 6 & MES 7 & MES 8 & MES 9 & MES 10 & MES 11 & MES 12 & AÑO1 & AÑO2 2 & AÑO 3 & AÑO 4 & AÑ 05 \\
\hline Sueldo Bàsico OPERADORES & & 1.475 .434 & 1.475 .434 & \begin{tabular}{|l|l|}
1.475 .434 \\
\end{tabular} & 1.475 .434 & 1.475 .434 & 1.475 .434 & 1.475 .434 & 1.475 .434 & 1.475 .434 & 1.475 .434 & 1.475 .434 & 1.475 .434 & 17.705 .208 & \begin{tabular}{|l|}
18.555 .058 \\
\end{tabular} & \begin{tabular}{|l|}
19.390 .036 \\
\end{tabular} & \begin{tabular}{|l|}
20.359 .537 \\
\end{tabular} & 21.377 .514 \\
\hline Auxilio de Transporte & & 166.280 & 166.280 & 166.280 & 166.280 & 166.280 & 166.280 & 166.280 & 166.280 & 166.280 & 166.280 & 166.280 & 166.280 & 1.995 .360 & 2.091 .137 & $\begin{array}{l}2.185 .238 \\
\end{array}$ & \begin{tabular}{|l|}
2.294 .500 \\
\end{tabular} & 2.409 .225 \\
\hline TOTAL DEVENGADO & & 1.641 .714 & 1.641.714 & 1.641 .714 & 1.641 .714 & 1.641 .714 & 1.641 .714 & 1.641.714 & 1.641 .714 & 1.641 .714 & \begin{tabular}{|l|l|}
1.641 .714 \\
\end{tabular} & 1.641 .714 & 1.641 .714 & 19.700 .568 & 20.646 .195 & 21.575 .274 & \begin{tabular}{|l|}
22.654 .038 \\
\end{tabular} & 23.786 .740 \\
\hline Salud & $8,5 \%$ & 125.412 & 125.412 & 125.412 & 125.412 & 125.412 & 125.412 & 125.412 & 125.412 & 125.412 & 125.412 & 125.412 & 125.412 & 1.504 .943 & 1.577 .180 & 1.648 .153 & 1.730 .561 & 1.817 .089 \\
\hline Pensiòn & $12,0 \%$ & 354.104 & 4.104 & 354.104 & 354.104 & 354.104 & 354.104 & 354.104 & 354.104 & 354.104 & 354.104 & 354.104 & 354.104 & 4.249 .250 & 2.226 .607 & 2.326 .804 & 2.443 .144 & 2.565 .302 \\
\hline $\operatorname{Arp}(0,514 \%)$ & $2,46 \%$ & 8.181 & $\begin{array}{r}8.181 \\
\end{array}$ & 8.181 & 8.181 & 8.181 & 8.181 & $\begin{array}{r}8.181 \\
\end{array}$ & 8.181 & 8.181 & 8.181 & 8.181 & 8.181 & 98.172 & 456.454 & 476.995 & 500.845 & 525.887 \\
\hline TOTAL SEGURIDAD SOCIAL & & 487.697 & 487.697 & 487.697 & 487.697 & 487.697 & 487.697 & 487.697 & 487.697 & 487.697 & 487.697 & 487.697 & 487.697 & 5.852 .364 & 4.260 .241 & 4.451 .952 & 4.674 .550 & 4.908.277 \\
\hline $\begin{array}{l}\text { SENA } \\
\end{array}$ & $2,0 \%$ & .017 & 017 & .017 & .017 & .017 & .017 & .017 & .017 & 59.017 & 9.017 & 59.017 & 59.017 & 708.208 & 371.101 & 387.801 & 407.191 & 427.550 \\
\hline ICBF & $3,0 \%$ & 88.526 & 88.526 & 88.526 & 88.526 & \begin{tabular}{l|l|}
88.526 \\
\end{tabular} & 88.526 & 88.526 & 88.526 & 88.526 & 88.526 & 88.526 & 88.526 & 1.062 .312 & 556.652 & 581.701 & 610.786 & 641.325 \\
\hline CAJA & $4,0 \%$ & 118.035 & 118.035 & 118.035 & 118.035 & 118.035 & 118.035 & 118.035 & 118.035 & 118.035 & 118.035 & 118.035 & 118.035 & 1.416 .417 & 742.202 & 775.601 & 814.381 & 855.101 \\
\hline TOTAL PARAFISCALES & & 265.578 & 5.578 & 265.578 & 265.578 & 265.578 & 265.578 & 265.578 & 5.578 & 55.578 & 265.578 & 265.578 & 265.578 & 3.186 .937 & 1.669 .955 & 1.745 .103 & 1.832 .358 & 1.923 .976 \\
\hline Primas & $8,3 \%$ & 136.810 & 136.810 & 136.810 & 136.810 & 136.810 & 136.810 & 136.810 & 136.810 & 136.810 & 136.810 & 136.810 & 136.810 & 1.641 .714 & 1.720 .516 & 1.797 .940 & 1.887 .836 & 1.982 .228 \\
\hline Cesantias & $8,3 \%$ & 136.810 & 136.810 & 136.810 & 136.810 & 136.810 & 136.810 & 136.810 & 136.810 & 136.810 & 136.810 & 136.810 & 136.810 & 1.641 .714 & 1.720 .516 & 1.797 .940 & 1.887 .836 & 1.982 .228 \\
\hline Intereses Cesantias & $1,0 \%$ & 16.417 & 16.417 & 16.417 & 16.417 & 16.417 & 16.417 & 16.417 & 16.417 & 16.417 & 16.417 & 16.417 & 16.417 & 197.006 & 206.462 & 215.753 & 226.540 & 237.867 \\
\hline Vacaciones & $4,17 \%$ & 68.405 & 68.405 & 68.405 & 68.405 & 68.405 & 68.405 & 68.405 & 68.405 & 68.405 & 68.405 & 68.405 & 68.405 & 820.857 & 860.258 & 898.970 & 943.918 & 991.114 \\
\hline TOTAL PRESTACIONES SOCIALES & & 358.441 & 358.441 & 358.441 & 358.441 & 358.441 & 358.441 & 358.441 & 358.441 & 358.441 & 358.441 & 358.441 & 358.441 & 4.301 .291 & 4.507 .753 & 4.710 .602 & 4.946.132 & 5.193 .438 \\
\hline TOTAL MANO DE OBRA & & 2.753 .430 & 2.753 .430 & 2.753 .430 & 2.753 .430 & 2.753 .430 & 2.753 .430 & 2.753 .430 & 2.753 .430 & 2.753 .430 & 2.753 .430 & 2.753 .430 & 2.753 .430 & 33.041 .160 & 31.084.144 & 32.482 .931 & 34.107.077 & \begin{tabular}{|l|l|}
35.812 .431 \\
\end{tabular} \\
\hline
\end{tabular}

Fuente: Autoras 


\section{Eurinda}

Ilustración 23. Nómina Director de producción

\begin{tabular}{|c|c|c|c|c|c|c|c|c|c|c|c|c|c|c|c|c|c|c|}
\hline & & & & & & & & & PROYECCIO & N DIRECTOR & DE PRODUC & CION & & & & & & \\
\hline CONCEPTO & $\%$ & MES 1 & MES 2 & MES 3 & MES 4 & MES 5 & MES 6 & MES 7 & MES 8 & MES 9 & MES 10 & MES 11 & MES 12 & AÑO1 & AÑO2 & AÑO 3 & AÑO 4 & AÑO 5 \\
\hline Sueldo Bàsico & & 850.000 & 850.000 & 850.000 & 850.000 & 850.000 & 850.000 & 850.000 & 850.000 & 850.000 & 850.000 & 850.000 & 850.000 & 10.200 .000 & 10.659 .000 & 11.191 .950 & 11.751 .548 & 12.339 .125 \\
\hline Auxilio de Transporte & & 83.140 & 83.140 & 83.140 & 83.140 & 83.140 & 83.140 & 83.140 & 83.140 & 83.140 & 83.140 & 83.140 & 83.140 & 997.680 & 1.042 .576 & 1.094 .704 & $\begin{array}{l}1.149 .440 \\
\end{array}$ & 1.206 .912 \\
\hline TOTAL DEVENGADO & & 933.140 & 933.140 & 933.140 & 933.140 & 933.140 & 933.140 & 933.140 & 933.140 & 933.140 & 933.140 & 933.140 & 933.140 & 11.197.680 & $\begin{array}{ll}11.701 .576 \\
\end{array}$ & 12.286 .654 & \begin{tabular}{|l|}
12.900 .987 \\
\end{tabular} & 13.546 .036 \\
\hline Salud & $8,5 \%$ & 72.250 & 72.250 & 72.250 & 72.250 & 72.250 & 72.250 & 72.250 & 72.250 & 72.250 & 72.250 & 72.250 & 72.250 & 867.000 & 906.015 & 951.316 & 998.882 & 1.048 .826 \\
\hline Pensiòn & $12,0 \%$ & 102.000 & 102.000 & 102.000 & 102.000 & 102.000 & 102.000 & 102.000 & 102.000 & 102.000 & 102.000 & 102.000 & 102.000 & 1.224 .000 & 1.279 .080 & 1.343 .034 & 1.410.186 & 1.480 .695 \\
\hline $\operatorname{Arp}(0,514 \%)$ & $2,46 \%$ & 20.910 & 20.910 & 20.910 & 20.910 & 20.910 & 20.910 & 20.910 & 20.910 & 20.910 & 20.910 & 20.910 & 20.910 & 250.920 & 262.211 & 275.322 & 289.088 & 303.542 \\
\hline TOTAL SEGURIDAD SOCIAL & & 195.160 & 195.160 & 195.160 & 195.160 & 195.160 & 195.160 & 195.160 & 195.160 & 195.160 & 195.160 & 195.160 & 195.160 & 2.341 .920 & 2.447 .306 & 2.569 .672 & 2.698 .155 & 2.833 .063 \\
\hline SENA & $2,0 \%$ & 17.000 & 17.000 & 17.000 & 17.000 & 17.000 & 17.000 & 17.000 & 7.000 & 17.000 & 17.000 & .000 & 17.000 & 204.000 & 213.180 & 223.839 & 235.031 & 246.782 \\
\hline ICBF & $3,0 \%$ & 25.500 & 25.500 & 25.500 & 25.500 & 25.500 & 25.500 & 25.500 & 25.500 & 25.500 & 25.500 & 25.500 & 25.500 & 306.000 & 319.770 & 335.759 & 352.546 & 370.174 \\
\hline CAJA & $4,0 \%$ & 34.000 & 34.000 & 34.000 & 34.000 & 34.000 & 34.000 & 34.000 & 34.000 & 34.000 & 34.000 & 34.000 & 34.000 & 408.000 & 426.360 & 447.678 & 470.062 & 493.565 \\
\hline TOTAL PARAFISCALES & & 76.500 & 76.500 & 76.500 & 76.500 & 76.500 & 76.500 & 76.500 & 76.500 & 76.500 & 76.500 & 76.500 & 76.500 & 918.000 & 959.310 & 1.007 .276 & 1.057 .639 & 1.110 .521 \\
\hline Primas & $8,3 \%$ & 77.762 & 77.762 & 77.762 & 77.762 & 77.762 & 77.762 & 77.762 & 77.762 & 77.762 & 77.762 & 7.762 & 77.762 & 933.140 & 975.131 & 1.023 .888 & 1.075 .082 & 1.128 .836 \\
\hline Cesantias & $8,3 \%$ & 77.762 & 77.762 & 77.762 & 77.762 & 77.762 & 77.762 & 77.762 & 77.762 & 77.762 & 77.762 & 77.762 & 77.762 & 933.140 & 975.131 & 1.023 .888 & 1.075 .082 & 1.128 .836 \\
\hline Intereses Cesantias & $1,0 \%$ & 9.331 & 9.331 & 9.331 & 9.331 & 9.331 & \begin{tabular}{|l|l|}
9.331 \\
\end{tabular} & 9.331 & 9.331 & 9.331 & 9.331 & 9.331 & 9.331 & 111.977 & 117.016 & 122.867 & 129.010 & 135.460 \\
\hline Vacaciones & $4,17 \%$ & 38.881 & 38.881 & 38.881 & 38.881 & 38.881 & 38.881 & 38.881 & 38.881 & 38.881 & 38.881 & 38.881 & 38.881 & 466.570 & 487.566 & 511.944 & 537.541 & 564.418 \\
\hline TOTAL PRESTACIONES SOCIALES & & 203.736 & 203.736 & 203.736 & 203.736 & 203.736 & 203.736 & 203.736 & 203.736 & 203.736 & 203.736 & 203.736 & 203.736 & 2.444 .827 & 2.554 .844 & 2.682 .586 & 2.816 .716 & 2.957 .551 \\
\hline TOTAL MANO DE OBRA & & 1.408 .536 & 1.408 .536 & 1.408 .536 & 1.408 .536 & 1.408 .536 & 1.408 .536 & 1.408 .536 & 1.408 .536 & 1.408 .536 & 1.408 .536 & \begin{tabular}{ll|}
1.408 .536 \\
\end{tabular} & 1.408 .536 & 16.902 .427 & \begin{tabular}{|l|}
17.663 .036 \\
\end{tabular} & \begin{tabular}{|l|}
18.546 .188 \\
\end{tabular} & \begin{tabular}{|l|}
19.473 .497 \\
\end{tabular} & 20.447 .172 \\
\hline
\end{tabular}

Fuente: Autoras

\section{Ilustración 24. Nómina administrativa}

\begin{tabular}{|c|c|c|c|c|c|c|c|c|c|c|c|c|c|c|c|c|c|c|}
\hline \multicolumn{19}{|c|}{ NOMINA ADMINISTRATIVA } \\
\hline CONCEPTO & $\%$ & Mes 1 & Mes 2 & Mes 3 & Mes 4 & Mes 5 & Mes 6 & Mes 7 & Mes 8 & Mes 9 & Mes 10 & Mes 11 & Mes 12 & \begin{tabular}{|l|} 
AÑO 1 \\
\end{tabular} & \begin{tabular}{|l|} 
AÑO 2 \\
\end{tabular} & \begin{tabular}{ll|} 
AÑO 3 \\
\end{tabular} & AÑO 4 & AÑO 5 \\
\hline Sueldo Bàsico Gerente General & & 1.500 .000 & 1.500 .000 & 1.500 .000 & 1.500 .000 & 1.500 .000 & 1.500 .000 & 1.500 .000 & 1.500 .000 & 1.500 .000 & 1.500 .000 & 1.500 .000 & 1.500 .000 & 18.000 .000 & \begin{tabular}{|l|}
18.864 .000 \\
\end{tabular} & 19.712 .880 & 20.698 .524 & 21.733 .450 \\
\hline Sueldo Bàsico Jefe de Ventas & & 1.500 .000 & 1.500 .000 & 1.500 .000 & 1.500 .000 & 1.500 .000 & 1.500 .000 & 1.500 .000 & 1.500 .000 & 1.500 .000 & 1.500 .000 & 1.500 .000 & 1.500 .000 & 18.000 .000 & 18.864 .000 & 19.712 .880 & 20.698 .524 & 21.733 .450 \\
\hline TOTAL DEVENGADO & & 3.000 .000 & 3.000 .000 & 3.000 .000 & 3.000 .000 & 3.000 .000 & 3.000 .000 & 3.000 .000 & 3.000 .000 & 3.000 .000 & 3.000 .000 & 3.000 .000 & 3.000 .000 & 39.000 .000 & 37.728 .000 & \begin{tabular}{l|l|}
39.425 .760 \\
\end{tabular} & $\begin{array}{ll}41.397 .048 \\
\end{array}$ & 43.466 .900 \\
\hline Salud & $8,5 \%$ & 255.000 & 255.000 & 255.000 & 255.000 & 255.000 & 255.000 & 255.000 & 255.000 & 255.000 & 255.000 & 255.000 & 255.000 & 3.060 .000 & 3.206 .880 & 3.351 .190 & 3.518 .749 & 3.694 .687 \\
\hline Pensiòn & $12,0 \%$ & 360.000 & 360.000 & 360.000 & 360.000 & 360.000 & 360.000 & 360.000 & 360.000 & 360.000 & 360.000 & 360.000 & 360.000 & 4.320 .000 & 4.527 .360 & 4.731 .091 & 4.967 .646 & 5.216 .028 \\
\hline $\operatorname{Arp}(0,514 \%)$ & $2,46 \%$ & 73.800 & 73.800 & 73.800 & 73.800 & 73.800 & 73.800 & 73.800 & 73.800 & 73.800 & 73.800 & 73.800 & 73.800 & 885.600 & 928.109 & 969.874 & 1.018 .367 & 1.069 .286 \\
\hline TOTAL SEGURIDAD SOCIAL & & 688.800 & 688.800 & 688.800 & 688.800 & 688.800 & 688.800 & 688.800 & 688.800 & 688.800 & 688.800 & 688.800 & 688.800 & 8.265 .600 & 8.662 .349 & 9.052 .154 & 9.504 .762 & 9.980 .000 \\
\hline SENA & $2,0 \%$ & 30.000 & 30.000 & 30.000 & 30.000 & 30.000 & 30.000 & 30.000 & 30.000 & 30.000 & 30.000 & 30.000 & 30.000 & 360.000 & 754.560 & 788.515 & \begin{tabular}{|l|}
827.941 \\
\end{tabular} & 869.338 \\
\hline ICBF & $3,0 \%$ & 45.000 & 45.000 & 45.000 & 45.000 & 45.000 & 45.000 & 45.000 & 45.000 & 45.000 & 45.000 & 45.000 & 45.000 & 540.000 & 1.131 .840 & 1.182 .773 & 1.241 .911 & 1.304 .007 \\
\hline CAJA & $4,0 \%$ & 60.000 & 60.000 & 60.000 & 60.000 & 60.000 & 60.000 & 60.000 & 60.000 & 60.000 & 60.000 & 60.000 & 60.000 & 720.000 & 1.509 .120 & 1.577 .030 & 1.655 .882 & 1.738 .676 \\
\hline TOTAL PARAFISCALES & & 135.000 & 135.000 & 135.000 & 135.000 & 135.000 & 135.000 & 135.000 & 135.000 & 135.000 & 135.000 & 135.000 & 135.000 & 1.620 .000 & 3.395 .520 & 3.548 .318 & 3.725 .734 & 3.912 .021 \\
\hline Primas & $8,3 \%$ & 250.000 & 250.000 & 250.000 & 250.000 & 250.000 & 250.000 & 250.000 & 250.000 & 250.000 & 250.000 & 250.000 & 250.000 & 3.000 .000 & 3.144 .000 & 3.285 .480 & 3.449 .754 & 3.622 .242 \\
\hline Cesantias & $8,3 \%$ & 250.000 & 250.000 & 250.000 & 250.000 & 250.000 & 250.000 & 250.000 & 250.000 & 250.000 & 250.000 & 250.000 & 250.000 & 3.000 .000 & 3.144 .000 & 3.285 .480 & 3.449 .754 & 3.622 .242 \\
\hline Intereses Cesantias & $1,0 \%$ & 30.000 & 30.000 & 30.000 & 30.000 & 30.000 & 30.000 & 30.000 & 30.000 & 30.000 & 30.000 & 30.000 & 30.000 & 360.000 & 377.280 & 394.258 & 413.970 & 434.669 \\
\hline Vacaciones & $4,17 \%$ & 125.000 & 125.000 & 125.000 & 125.000 & 125.000 & 125.000 & 125.000 & 125.000 & 125.000 & 125.000 & 125.000 & 125.000 & 1.500 .000 & 1.572 .000 & 1.642 .740 & 1.724 .877 & 1.811 .121 \\
\hline TOTAL PRESTACIONES SOCIALES & & 655.000 & 655.000 & 655.000 & 655.000 & 655.000 & 655.000 & 655.000 & 655.000 & 655.000 & 655.000 & 655.000 & 655.000 & 7.860 .000 & 8.237 .280 & \begin{tabular}{l|l|}
8.607 .958 \\
\end{tabular} & 9.038 .355 & 9.490 .273 \\
\hline TOTAL MANO DE OBRA & & 4.478 .800 & & & & & & & & & & & & 56.745 .600 & \begin{tabular}{|l|}
58.023 .149 \\
\end{tabular} & 60.634.190 & 63.665.900 & 66.849 .195 \\
\hline
\end{tabular}

Fuente: Autoras 


\section{Ilustración 25. Nómina de ventas}

\begin{tabular}{|c|c|c|c|c|c|c|c|c|c|c|c|c|c|c|c|c|c|c|}
\hline \multicolumn{19}{|c|}{ PROYECCION NOMINA VENDEDOR } \\
\hline CONCEPTO & $\%$ & MES 1 & MES 2 & MES 3 & MES 4 & MES 5 & MES 6 & MES 7 & MES 8 & MES 9 & MES 10 & MES 11 & MES 12 & AÑO 1 & AÑO 2 & AÑO 3 & AÑO 4 & AÑN 5 \\
\hline Sueldo Bàsico Vendedor & & 737.717 & 737.717 & 737.717 & 737.717 & 737.717 & 737.717 & 737.717 & 737.717 & 737.717 & 737.717 & 737.717 & 737.717 & 8.852 .604 & 9.277 .529 & 9.695 .018 & 10.179 .769 & $\mid 10.688 .757$ \\
\hline Auxilio de Transporte & & 83.140 & 83.140 & 83.140 & 83.140 & 83.140 & 83.140 & 83.140 & 83.140 & 83.140 & 83.140 & 83.140 & 83.140 & 997.680 & 1.045.569 & 1.092 .619 & 1.147.250 & \begin{tabular}{|l}
1.204 .613 \\
\end{tabular} \\
\hline TOTAL DEVENGADO & & 820.857 & 820.857 & 820.857 & 820.857 & 820.857 & 820.857 & 820.857 & 820.857 & 820.857 & 820.857 & 820.857 & 820.857 & 9.850 .284 & \begin{tabular}{|l|l|}
10.323 .098 \\
\end{tabular} & \begin{tabular}{|l|}
10.787 .637 \\
\end{tabular} & 11.327 .019 & 11.893 .370 \\
\hline Pensiòn & $12,0 \%$ & 88.526 & 88.526 & 88.526 & 88.526 & 88.526 & 88.526 & 88.526 & 88.526 & 88.526 & 88.526 & 88.526 & 88.526 & 1.062 .312 & 1.113 .303 & 1.163 .402 & 1.221 .572 & 1.282 .651 \\
\hline $\operatorname{Arp}(0,514 \%)$ & $2,46 \%$ & 18.148 & 18.148 & 18.148 & 18.148 & 18.148 & 18.148 & 18.148 & 18.148 & 18.148 & 18.148 & 18.148 & 18.148 & 217.774 & 228.227 & 238.497 & 250.422 & 262.943 \\
\hline TOTAL SEGURIDAD SOCIAL & & 169.380 & 169.380 & 169.380 & $\mathbf{1 6 9 . 3 8 0}$ & 169.380 & 169.380 & 169.380 & 169.380 & 169.380 & 169.380 & 169.380 & 169.380 & 2.032 .558 & 2.130 .121 & 2.225.976 & 2.337 .275 & 2.454 .139 \\
\hline SENA & $2,0 \%$ & 14.754 & 14.754 & 14.754 & 14.754 & 14.754 & 14.754 & 14.754 & 14.754 & 14.754 & 14.754 & 14.754 & 14.754 & 177.052 & 185.551 & 193.900 & 203.595 & 213.775 \\
\hline CAJA & $4,0 \%$ & 29.509 & 29.509 & 29.509 & 29.509 & 29.509 & 29.509 & 29.509 & 29.509 & 29.509 & 29.509 & 29.509 & 29.509 & 354.104 & 371.101 & 387.801 & 407.191 & 427.550 \\
\hline TOTAL PARAFISCALES & & 66.395 & 66.395 & 66.395 & 66.395 & 66.395 & 66.395 & 66.395 & 66.395 & 66.395 & 66.395 & 66.395 & 66.395 & 796.734 & 834.978 & 872.552 & 916.179 & 961.988 \\
\hline Primas & $8,3 \%$ & 68.405 & 68.405 & 68.405 & 68.405 & 68.405 & 68.405 & 68.405 & 68.405 & 68.405 & 68.405 & 68.405 & 68.405 & 820.857 & 860.258 & 898.970 & 943.918 & 991.114 \\
\hline Cesantias & $8,3 \%$ & 68.405 & 68.405 & 68.405 & 68.405 & 68.405 & 68.405 & 68.405 & 68.405 & 68.405 & 68.405 & 68.405 & 68.405 & 820.857 & 860.258 & 898.970 & 943.918 & 991.114 \\
\hline Intereses Cesantias & $12,0 \%$ & 8.209 & 8.209 & 8.209 & 8.209 & 8.209 & 8.209 & 8.209 & 8.209 & 8.209 & 8.209 & 8.209 & 8.209 & 98.503 & 103.231 & 107.876 & 113.270 & 118.934 \\
\hline Vacaciones & $4,17 \%$ & 34.202 & 34.202 & 34.202 & 34.202 & 34.202 & 34.202 & 34.202 & 34.202 & 34.202 & 34.202 & 34.202 & 34.202 & 410.429 & 430.129 & 449.485 & 471.959 & 495.557 \\
\hline TOTAL PRESTACIONES SOCIALES & & 179.220 & 179.220 & 179.220 & 179.220 & 179.220 & 179.220 & 179.220 & 179.220 & 179.220 & 179.220 & 179.220 & 179.220 & 2.150 .645 & 2.253 .876 & 2.355 .301 & 2.473 .066 & 2.596 .719 \\
\hline TOTAL MANO DE OBRA & & 1.235 .852 & 1.235 .852 & 1.235 .852 & 1.235 .852 & \begin{tabular}{|l|l|}
1.235 .852 \\
\end{tabular} & 1.235.852 & \begin{tabular}{|l|}
.235 .852 \\
\end{tabular} & 1.235 .852 & 1.235 .852 & \begin{tabular}{|l|l|} 
& \\
\end{tabular} & 1.235 .852 & 1.235 .852 & 14.830 .222 & \begin{tabular}{|l|l|}
15.542 .072 \\
\end{tabular} & 16.241 .465 & \begin{tabular}{|l|l}
17.053 .539 \\
\end{tabular} & 17.906 .216 \\
\hline
\end{tabular}

Fuente: Autoras 


\section{ESTUDIO ORGANIZACIONAL}

\section{Organigrama}

Luzinda SAS, ha creado los cargos necesarios para satisfacer las necesidades de operaciòn de la empresa, con este organigrama se conoceràn de manera clara los cargos existentes en la organizaciòn y asi delimitar las respomsabilidades y funciones que cada uno de ellos tiene:

Ilustración 26. Organigrama

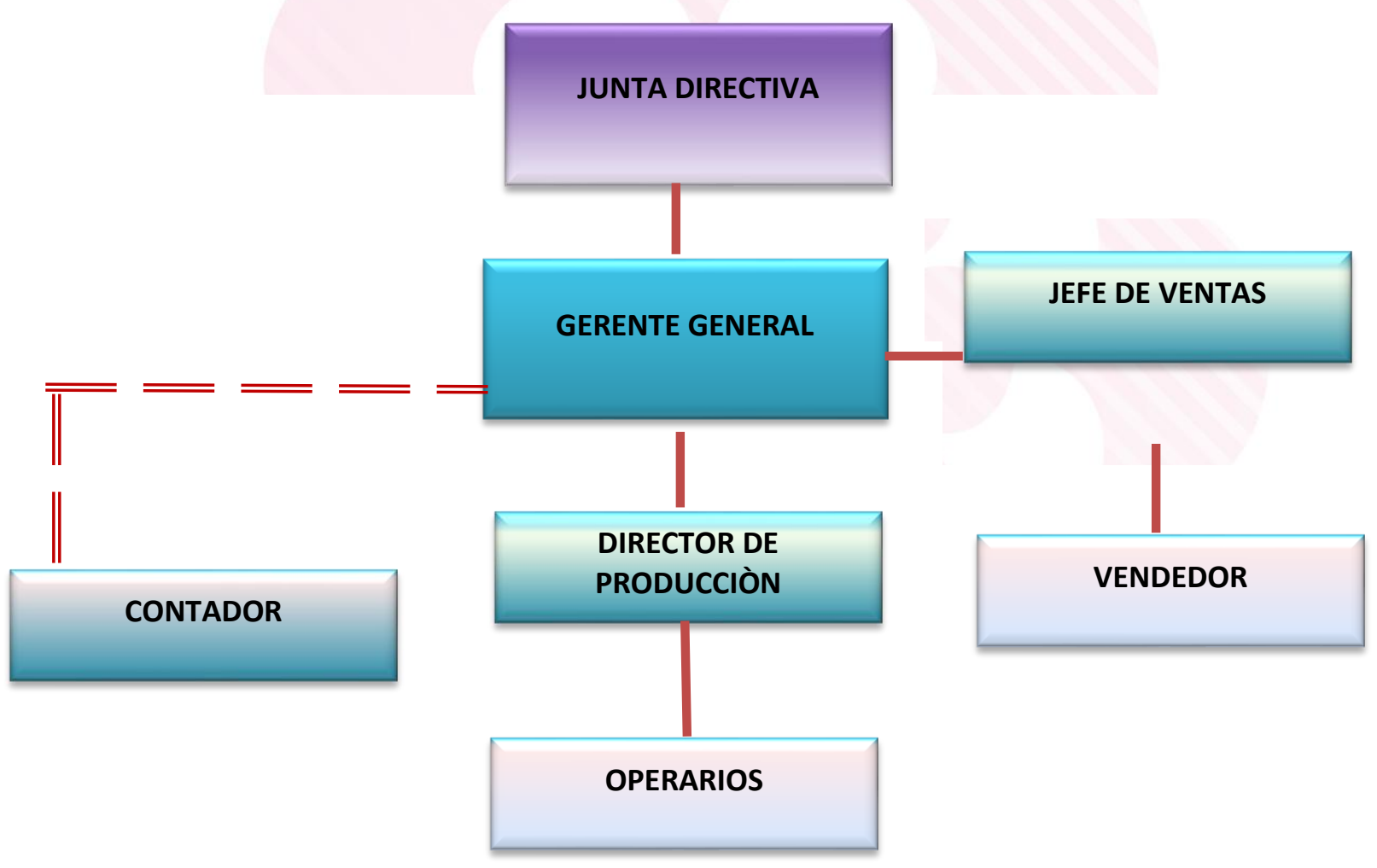

Fuente: Autoras 
Manual de funciones

Ilustración 27. Manual de funciones

CARGO: GERENTE GENERAL

SUELDO: $\$ 1.500 .000$

DEPENDENCIA: JUNTA DIRECTIVA

\section{FUNCIONES Y RESPONSABILIDADES}

1. Dirigir, coordinar y controlar las actividades de la Compañía.

2. Ordenar los gastos, dictar los actos, realizar las operaciones y celebrar los contratos y convenios que se requieran para el normal funcionamiento de la empresa.

3. Nombrar y remover el personal de la empresa y establecer el manual específico de funciones y requisitos de la entidad.

4. Administrar y velar por la adecuada utilización de los bienes y fondos que constituyen el patrimonio de la empresa.

5. Distribuir el personal en los cargos que se establecen en la planta de personal, teniendo en cuenta la estructura interna y las necesidades de la empresa.

6. Dirigir y supervisar la prestación de los servicios, garantizando excelentes relaciones con los clientes internos y externos.

7. Dirigir las relaciones públicas de la organización.

8. Las demás funciones relacionadas con la naturaleza del cargo.

\section{AUTORIDAD}

Tiene toda la autonomía para la toma de decisiones en cuanto a: Contratación, autorización de pagos, ejecución de contrato con los clientes, inversiones, alianzas entre otros. 


\section{PERFIL DEL CARGO}

\section{EDUCACION:}

Título de formación superior en Administración de Empresas

\section{HABILIDADES:}

Liderazgo, solución de problemas, sentido de la urgencia, trabajo en equipo y organización.

\section{CARGO: DIRECTOR DE PRODUCCIÓN}

SUELDO: $\$ 1.000 .000$

DEPENDENCIA: GERENTE ADMINISTRATIVO Y OPERATIVO

\section{FUNCIONES Y RESPONSABILIDADES}

1. Dirigir y coordinar la producción

2. Supervisar el adecuado uso de la materia prima en la producción

3. Establecer las necesidades de materia prima en el momento adecuado para que la producción fluya de manera óptima.

4. Seguir los diseños entregados por la gerencia para la producción del producto.

5. Informar irregularidades presentadas con el desarrollo de la producción.

6. Informar a gerencia situaciones o irregularidades presentadas con los operarios

7. Informar a gerencia en caso de requerir personal adicional para producción.

8. Debe velar por la calidad del producto 
9. Las demás funciones relacionadas con la naturaleza del cargo.

\section{AUTORIDAD}

Tiene toda la autonomía para la toma de decisiones en cuanto a: prioridad en definir prioridades de la producción

\section{PERFIL DEL CARGO}

EDUCACIÓN:

Formación en producción y/o elaboración de calzado.

\section{HABILIDADES:}

Liderazgo, solución de problemas, pro actividad, trabajo en equipo y organización.

\section{CARGO: OPERARIO}

SUELDO: 737.717

DEPENDENCIA: DIRECTOR DE PRODUCCIÓN

\section{FUNCIONES Y RESPONSABILIDADES}

1. Elaboración del calzado

2. Ceñirse a los diseños entregados para la elaboración del producto

3. Informar a su superior defectos de la materia prima que comprometan la calidad del producto 
4. Informar de averías en maquinaria o herramientas de trabajo

5. Debe velar por la calidad del producto

6. Las demás funciones relacionadas con la naturaleza del cargo.

\section{AUTORIDAD}

Tiene toda la autonomía para la toma de decisiones en cuanto a: No posee autoridad.

\section{PERFIL DEL CARGO}

\section{EDUCACIÓN:}

Bachiller / Proceso productivo del calzado

\section{HABILIDADES:}

Trabajo en equipo, orden, concentración.

\section{CARGO: JEFE DE VENTAS \\ SUELDO: $\$ 1.500 .000$ \\ DEPENDENCIA: GERENTE ADMINISTRATIVO Y OPERATIVO}

\section{FUNCIONES Y RESPONSABILIDADES}

1. Realizar cuando sea necesario y pertinente el cierre de la Negociación con clientes, buscando siempre mantener las mejores oportunidades.

2. Velar por el mantenimiento y fortalecimiento de la marca, la imagen y el servicio a nivel general. 
3. Dar a conocer a los clientes y posibles clientes la funcionalidad del producto.

4. Capacitar y asesorar al cliente de los procedimientos del servicio.

5. Coordinar visitas periódicas para retro-alimentar necesidades e inquietudes del cliente.

6. Garantizar que toda queja o reclamo, observación o sugerencia por parte de los clientes sea atendida de manera inmediata.

7. Las demás funciones relacionadas con la naturaleza del cargo.

\section{AUTORIDAD}

Posee toda la autoridad para tomar decisiones en cuanto a: ejecución de contrato con los clientes.

\section{PERFIL DEL CARGO}

\section{EDUCACIÓN:}

Formación en ventas

\section{HABILIDADES:}

Liderazgo, trabajo en equipo, amabilidad, orden, sentido de la urgencia. 


\section{CARGO: VENDEDOR}

\section{SUELDO: 737.717}

\section{DEPENDENCIA: GERENTE ADMINISTRATIVO Y COMERCIAL}

\section{FUNCIONES Y RESPONSABILIDADES}

1. Dar a conocer a los clientes y posibles clientes la funcionalidad del producto

2. Realizar apertura y cierre de la venta con el cliente, buscando siempre captar nuevas oportunidades de negocio.

3. Ofrecer un buen servicio de cara al cliente, cálido, amable que permita el fortalecimiento de la marca, la imagen y el servicio a nivel general.

4. Mantener buenas relaciones con los clientes.

5. Atender los requerimientos posventa de los clientes.

6. Manejo de efectivo de las ventas del día.

7. Las demás funciones relacionadas con la naturaleza del cargo.

\section{AUTORIDAD}

Posee toda la autoridad para tomar decisiones en cuanto a: Cierre de ventas con los clientes.

\section{PERFIL DEL CARGO}

\section{EDUCACION:}

Bachiller y Formación en ventas. 
HABILIDADES:

Habilidades Interpersonales, habilidades para las ventas, responsabilidad, compromiso y Organización.

Fuente: Autoras

\section{REQUISITOS LEGALES}

Luzinda SAS. Será una sociedad por acciones simplificadas (S.A.S.)

Es un tipo de empresa creado por la LEY 1258 de 2008, se caracteriza por ser un tipo de estructura societaria de capital, que puede ser constituida por una o varias personas naturales o jurídicas, cuya responsabilidad va hasta por el monto de sus aportes, este tipo de organización permite a los socios definir las pautas por las cuales han de gobernarse sus relaciones jurídicas.

La constitución puede hacerse mediante:

- Documento privado, autenticado, reconocido o con presentación personal por sus signatarios s (Párrafo 1 artículo 5 Ley 1258 de 2008, Artículo 40 Ccio).

- Mediante escritura pública de constitución, cuando hay aporte de inmuebles (Parágrafo $2^{\circ}$ Artículo $5^{\circ}$, Artículos $6^{\circ}$ y $7^{\circ}$ ), o cuando los accionistas lo consideren de utilidad. 
Sin importar la forma en la que se constituya deben tenerse en cuenta los siguientes requisitos:

- Nombre, documento de identidad y domicilio de los accionistas.

- Razón social o denominación de la sociedad.

- El domicilio principal de la sociedad y el de las distintas sucursales que se establezcan en el mismo acto de constitución.

- El término de duración y objeto social.

- El capital autorizado, suscrito y pagado, la clase, número y valor nominal de las acciones representativas del capital y la forma y términos en que estas deberán pagarse.

- La forma de administración y el nombre, documento de identidad y facultades de sus administradores. En todo caso, deberá designarse cuando menos un representante 


\section{Ilustración 28. Requisitos inscripción en cámara y comercio}

1. Documentos necesarios para registrarse como persona jurídica ante la CCB:

- Original del documento de identidad.

- Formulario del Registro Único Tributario (RUT).

- Formularios disponibles en las sedes de la CCB.

- Formulario de Registro.Único. Emoresarial..y. Social (RUES)

- Carátula única empresarial y anexos, según corresponda (Persona.Natural)

- Formulario de Registro con otras entidades

Con este formulario, la CCB envía la información a la Secretaría de Hacienda Distrital con el propósito de llevar a cabo la inscripción en el Registro de Información Tributaria (RIT), siempre y cuando las actividades que va a realizar se lleven a cabo en Bogotá y estén gravadas con el Impuesto de Industria y Comercio (ICA).

Tenga en cuenta que estos formularios deben ser diligenciados completamente y firmados por la persona natural o representante legal.

Recomendaciones al diligenciar los formularios

- Verifique que el nombre registrado en el formulario del RUT sea idéntico al registrado en el Formulario Registro Único Empresarial y Social (RUES) y al formulario adicional de registro con otras entidades.

- Revise que el número de teléfono registrado en el formulario del RUT sea idéntico al registrado en el formulario del RUES y al formulario adicional de registro con otras entidades.

Todos los formularios están disponibles también en las diferentes Sedes Empresariales de la ССв.

Recuperado de: http://www.ccb.org.co/Cree-su-empresa/Pasos-para-crear-

empresa/Constituya-su-empresa-como-persona-natural-persona-juridica-o-establecimiento-

\section{$\underline{\text { de-comercio }}$}




\section{GASTOS ADMINISTRATIVOS}

Para que Luzinda SAS, inicie su operación es necesario contemplar aspectos como el pago de un arriendo, servicios, nóminas y demás que se requieran para el arranque de la empresa, a continuación, se relacionan estos gastos administrativos:

\section{Ilustración 29. Relación de gastos administrativos}

\begin{tabular}{|c|c|c|c|c|c|c|c|c|c|c|c|c|c|c|c|c|c|}
\hline & MES 1 & MES 2 & MES 3 & MES 4 & MES 5 & MES 6 & MES 7 & MES 8 & MES 9 & MES 10 & MES 11 & MES 12 & Año1 & Año2 & Año3 & Año4 & Año 5 \\
\hline \multicolumn{18}{|l|}{ GASTOS ADMINISTRATIVOS } \\
\hline Arriendo $(40 \%)$ & 1.520 .000 & 1.520 .000 & 1.520 .000 & 1.520 .000 & 1.520 .000 & 1.520 .000 & 1.520 .000 & 1.520 .000 & 1.520 .000 & 1.520 .000 & 1.520 .000 & 1.520 .000 & 18.240 .000 & 19.115.520 & 19.975 .718 & 20.974.504 & 22.023 .230 \\
\hline Elementos de protecciòn personal & 50.000 & 50.000 & 50.000 & 50.000 & 50.000 & 50.000 & 50.000 & 50.000 & 50.000 & 50.000 & 50.000 & 50.000 & 600.000 & $\begin{array}{r}628.800 \\
\end{array}$ & $\begin{aligned} 657.096 \\
\end{aligned}$ & $\begin{array}{l}689.951 \\
\end{array}$ & 724.448 \\
\hline Telefono e Internet (60\%) & 78.000 & 78.000 & 78.000 & 78.000 & 78.000 & 78.000 & 78.000 & 78.000 & 78.000 & 78.000 & 78.000 & 78.000 & 936.000 & 980.928 & 1.025 .070 & 1.076 .323 & 1.130 .139 \\
\hline Agua (40\%) & 56.000 & 56.000 & 56.000 & 56.000 & 56.000 & 56.000 & 56.000 & 56.000 & 56.000 & 56.000 & 56.000 & 56.000 & 672.000 & 704.256 & \begin{tabular}{rl|}
735.948 \\
\end{tabular} & 772.745 & 811.382 \\
\hline Luz (40\%) & 48.000 & 48.000 & 48.000 & 48.000 & 48.000 & 48.000 & 48.000 & 48.000 & 48.000 & 48.000 & 48.000 & 48.000 & 576.000 & 603.648 & 630.812 & 662.353 & 695.470 \\
\hline Depreciación muebles y enseres & 52.683 & 52.683 & 52.683 & 52.683 & 52.683 & 52.683 & 52.683 & 52.683 & 52.683 & 52.683 & 52.683 & 52.683 & 632.200 & 632.200 & 632.200 & 632.200 & 632.200 \\
\hline Honorarios Contador & 500.000 & 500.000 & 500.000 & 500.000 & 500.000 & 500.000 & 500.000 & 500.000 & 500.000 & 500.000 & 500.000 & 500.000 & 6.000 .000 & 6.288 .000 & 6.570 .960 & 6.899 .508 & 7.244 .483 \\
\hline SUBTOTAL & S 2.304.683,33 & \$ 2.304.683,33 & \begin{tabular}{|l|l|} 
S 2.304.683,33 \\
\end{tabular} & S 2.304.683,33 & S 2.304.683,33 & S 2.304.683,33 & \begin{tabular}{|l|l|} 
S 2.304.683,33 \\
\end{tabular} & \begin{tabular}{|l|l|} 
S 2.304.683,33 \\
\end{tabular} & \begin{tabular}{|l|l|} 
S 2.304.683,33 \\
\end{tabular} & \begin{tabular}{|l|l|} 
S 2.304.683,33 \\
\end{tabular} & S 2.304.688,33 & $\$ 2.304 .683,33$ & 27.656 .200 & 28.953 .352 & 30.227 .804 & 31.707 .584 & 33.261 .353 \\
\hline
\end{tabular}

Fuente: Autoras

Ilustración 30. Relación de otros gastos

\begin{tabular}{|c|c|c|c|c|c|c|c|c|c|c|c|c|c|c|c|c|c|}
\hline & MES 1 & MES 2 & MES 3 & MES 4 & MES 5 & MES 6 & MES 7 & MES 8 & MES 9 & MES 10 & MES 11 & MES 12 & Año1 & Año2 & Año3 & Año4 & Año 5 \\
\hline \multicolumn{18}{|l|}{ GASTOS PRODUCCION } \\
\hline Arriendo (60\%) & 2.280 .000 & 2.280 .000 & 2.280 .000 & 2.280 .000 & 2.280 .000 & 2.280 .000 & 2.280 .000 & 2.280 .000 & 2.280 .000 & 2.280 .000 & 2.280 .000 & 2.280 .000 & 27.360 .000 & 28.673 .280 & 29.963 .578 & 31.461 .756 & 33.034 .844 \\
\hline Telefono e Internet (40\%) & 52.000 & 52.000 & 52.000 & 52.000 & 52.000 & 52.000 & 52.000 & 52.000 & 52.000 & 52.000 & 52.000 & 52.000 & $\begin{array}{l}624.000 \\
\end{array}$ & $\begin{array}{r}653.952 \\
\end{array}$ & $\begin{array}{l}683.380 \\
\end{array}$ & 717.549 & 753.426 \\
\hline Agua (60\%) & 84.000 & 84.000 & 84.000 & 84.000 & 84.000 & 84.000 & 84.000 & 84.000 & 84.000 & 84.000 & 84.000 & 84.000 & 1.008 .000 & 1.056 .384 & 1.103 .921 & \begin{tabular}{|l|l|}
1.159 .117 \\
\end{tabular} & 1.217 .073 \\
\hline Luz (60\%) & 72.000 & 72.000 & $\begin{array}{r}72.000 \\
\end{array}$ & 72.000 & $\begin{array}{r}72.000 \\
\end{array}$ & 72.000 & 72.000 & 72.000 & \begin{tabular}{|l}
72.000 \\
\end{tabular} & \begin{tabular}{|l|}
72.000 \\
\end{tabular} & 72.000 & 72.000 & 864.000 & 905.472 & \begin{tabular}{|l|l|}
946.218 \\
\end{tabular} & 993.529 & 1.043 .206 \\
\hline SUBTOTAL & S 2.488.000,00 & S 2.488.000,00 & S 2.488.000,00 & S 2.488.000,00 & S 2.488.000,00 & S 2.488.000,00 & S 2.488.000,00 & S 2.488.000,00 & S 2.488.000,00 & S 2.488.000,00 & \$ 2.488.000,00 & S 2.488.000,00 & 29.856 .000 & 31.289 .088 & 32.697 .097 & 34.331.952 & 36.048 .549 \\
\hline \multicolumn{18}{|l|}{ GASTOS DE PUBLICIDAD } \\
\hline \begin{tabular}{|l} 
Pendones \\
\end{tabular} & 100.000 & & & & & 100.000 & & & 100.000 & & & 100.000 & 400.000 & 419.200 & 438.064 & 459.967 & 482.966 \\
\hline Tarjetas presentacion & 150.000 & & & & & & & & & & & & 150.000 & 157.200 & \begin{tabular}{ll|l}
164.274 \\
\end{tabular} & $\begin{array}{ll}172.488 \\
\end{array}$ & 181.112 \\
\hline Volantes publicitarios & $\begin{array}{r}260.000 \\
\end{array}$ & & & & & & & 260.000 & & & & & 520.000 & 544.960 & 569.483 & 597.957 & 627.855 \\
\hline SUBTOTAL & $\begin{array}{ll}\text { S } 510.000,00 \\
\end{array}$ & & & & & & & & & & & & 1.070 .000 & 1.121 .360 & 1.171 .821 & 1.230 .412 & 1.291 .933 \\
\hline TOTAL GASTOS & S 5.409.263,33 & & & & & & & & & & & & 59.861.160 & 62.642 .760 & 65.375 .682 & 68.548 .908 & 71.880 .796 \\
\hline
\end{tabular}

Fuente: Autoras 


\section{Metodologías de Motivación}

Las técnicas de motivación a utilizar se basan en hacer sentir al personal que son parte importante de Luzinda, esto a través de:

$\checkmark$ Buena adecuación del puesto de trabajo con las herramientas necesarias para sus labores, y propender por un entorno laboral agradable.

$\checkmark$ Capacitaciones.

$\checkmark$ Reconocimiento a través de elección del empleado del mes.

$\checkmark$ Cumplir con el pago a tiempo del salario.

$\checkmark$ Generar espacios de comunicación.

\section{Mecanismos de Liderazgo}

El tipo de liderazgo a seguir será el transformacional el cual consiste en buscar la motivación de los empleados, creando una relación más cercana, entendiendo que no solo están para hacer dinero, esto se llevará a cabo haciéndoles participe de los logros de la empresa, así como teniendo en cuenta sus ideas para el beneficio de la misma, demostrando interés en su trabajo, además mostrar con nuestro ejemplo que se puede confiar en nuestras acciones 


\section{ESTUDIO FINANCIERO}

\section{Políticas financieras}

- La empresa no tendrá créditos bancarios, puesto los socios aportan el dinero con el que la empresa iniciara sus operaciones.

- Luzinda SAS, realizara sus ventas de contado dado el tipo de producto.

- El pago de compras de materia prima se regirá por los siguientes parámetros:

Ilustración 31. Política de compras

\begin{tabular}{|c|c|c|c|c|c|c|c|c|}
\hline CONTADO & CONTADO & CREDITO & CONTADO & CREDITO & CONTADO & CREDITO & CONTADO & CREDITO \\
\hline $100 \%$ & $70 \%$ & $30 \%$ & $70 \%$ & $30 \%$ & $70 \%$ & $30 \%$ & $70 \%$ & $30 \%$ \\
\hline AÑO 1 & \multicolumn{2}{|c|}{ AÑO 2 } & \multicolumn{2}{|c|}{ AÑO 3 } & \multicolumn{2}{c|}{ AÑO 4 } & \multicolumn{2}{c|}{ AÑO 5 } \\
\hline
\end{tabular}

Fuente: Autoras

- Luzinda SAS debe declarar y pagar a la Dirección de impuestos y Aduanas Nacionales

(Dian), el impuesto sobre la renta con una tarifa del $25 \%$.

- Las proyecciones se realizan teniendo en cuenta el comportamiento de la inflación

\section{Punto de equilibrio}

Ilustración 32. Punto de equilibrio

\begin{tabular}{c|lr} 
PUNTO DE EQUILIBRIO OPERATIVO \\
\hline Costos fijos & $\$$ & 15.285 .881 \\
Costos variables & $\$$ & 36.605 \\
Precio de venta & $\$$ & 153.000 \\
RESULTADO $($ UNIDADES AL MES $)=$ & \multicolumn{2}{|c}{$\mathbf{1 3 1}$}
\end{tabular}

Fuente: Autoras 
El punto de equilibrio operativo indica que las unidades a vender por Luzinda deben ser

131, pero para determinar con que unidades se deben vender y generar utilidad se calcula el punto de equilibrio financiero, para ello se realiza el Estado de resultado operativo y financiero:

Ilustración 33. Estado de Resultados Operativo y financiero

ESTADO DE RESULTADOS OPERATIVO Y FINANCIERO EMPRESA Luzinda SAS

\begin{tabular}{l|l} 
& \multicolumn{1}{c}{ OPERATIVO } \\
& \\
\hline Ventas & $\$ 20.093 .208$ \\
\hline Costo Variable & $\$ 4.807 .328$ \\
\hline Margen de Contribuciòn & $\$ 15.285 .881$ \\
\hline Costos Fijos & $\$ 15.285 .881$ \\
\hline Utilidad antes de impuesto & $\$$ \\
\hline Imporenta 25\% & \\
\hline Utilidad Neta &
\end{tabular}

punto equilibrio financiero

\begin{tabular}{lr}
$\$ 23.619 .214$ \\
\hline$\$ \quad 116.395$
\end{tabular}

IGUAL A

FINANCIERO

SUPUESTO

FINANCIERO

REAL

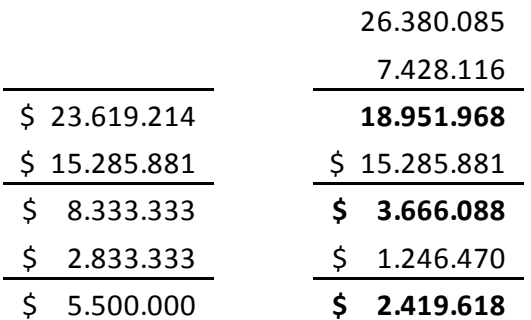

Fuente: Autoras

Mediante los resultados del estado de resultados financiero final, se determina que las unidades que Luzinda SAS debe vender al mes son de 203 para alcanzar su punto de equilibrio financiero. 
Para asignar el precio del producto se observó el comercio en el sector de Chapinero para conocer el precio del producto del sector, por otro lado tuvimos en cuenta la percepción de precios de los consumidores, y así determinar qué valor invierten ellos en la compra de zapatos:

Ilustración 34. Dinero a invertir a la hora de comprar zapatos

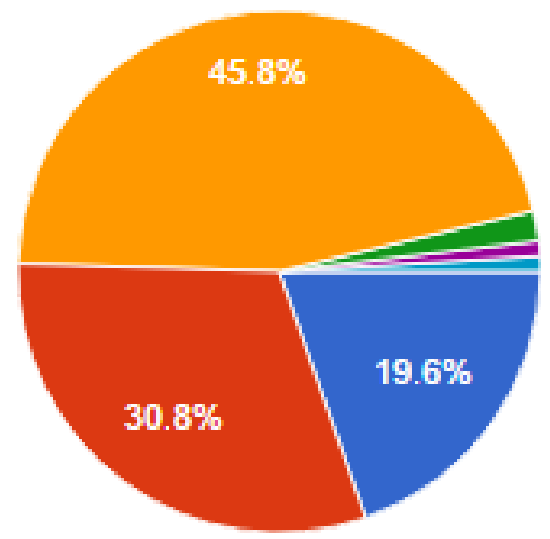

DE $\$ 80.000$ A $\$ 100.000$

DE $\$ 100.000$ A $\$ 130.000$

DE $\$ 130.000$ A $\$ 180.000$

200000

200.000

Más de $\$ 200000$

Fuente: Autoras

El $45.8 \%$ de la muestra invierte entre $\$ 130.000$ a $\$ 180.000$ para la compra de unos zapatos, seguido por un $30.8 \%$ que está dispuesto a pagar entre \$100.000 a \$130.000, esto nos permite establecer un precio de \$153.000, además que es un precio que está acorde con los del sector es un precio que permite generar utilidades a Luzinda SAS.

Con este precio la margen de contribución es de $76.08 \%$ 


\section{Presupuesto de ventas}

Se realiza un presupuesto de ventas de Luzinda SAS, para observar el comportamiento de sus ventas hasta el año 5, teniendo en cuenta el índice de la inflación, el cual tendrá el siguiente comportamiento:

Ilustración 35. Comportamiento de la inflación

\begin{tabular}{|c|c|c|c|c|c|}
\hline Inflación & Año1 & Año2 & Año3 & Año4 & Año5 \\
\cline { 2 - 6 } Proyectada & $4,80 \%$ & $4,50 \%$ & $5,00 \%$ & $5,00 \%$ & $5,00 \%$ \\
\hline
\end{tabular}

Fuente: Autoras

Se tiene además el comportamiento de las ventas reales del sector de los últimos cinco años, las cuales se promediaron y se le asignó a cada mes un peso de participación sobre las ventas reales al año.

Ilustración 36. Ventas reales del sector

\begin{tabular}{|c|c|c|c|c|c|c|c|}
\hline \multirow[b]{2}{*}{ Mes } & \multicolumn{5}{|c|}{ Ventas reales sector } & \multirow[b]{2}{*}{ Promedio } & \multirow[b]{2}{*}{ Peso } \\
\hline & 2016 & 2015 & 2014 & 2013 & 2012 & & \\
\hline Enero & 87,7 & 82,9 & 81,2 & 79,2 & 81,0 & 82,4 & $7,05 \%$ \\
\hline Febrero & 88,5 & 85,5 & 85,6 & 73,9 & 89,8 & 84,7 & $7,24 \%$ \\
\hline Marzo & 90,7 & 89,1 & 92,1 & 75,4 & 110,5 & 91,6 & $7,83 \%$ \\
\hline Abril & 96,7 & 92,6 & 96,4 & 91,1 & 95,7 & 94,5 & $8,09 \%$ \\
\hline Mayo & 96,0 & 93,3 & 96,3 & 91,8 & 97,6 & 95,0 & $8,13 \%$ \\
\hline Junio & 92,8 & 81,3 & 80,4 & 69,6 & 82,3 & 81,3 & $6,95 \%$ \\
\hline Julio & 94,0 & 92,6 & 98,4 & 80,5 & 90,0 & 91,1 & $7,79 \%$ \\
\hline Agosto & 91,6 & 92,1 & 94,3 & 78,7 & 89,4 & 89,2 & $7,63 \%$ \\
\hline Septiembre & 101,9 & 103,2 & 106,9 & 96,4 & 93,8 & 100,4 & $8,59 \%$ \\
\hline Octubre & 100,5 & 102,3 & 114,3 & 101,5 & 119,7 & 107,7 & $9,21 \%$ \\
\hline Noviembre & 119,1 & 115,5 & 116,7 & 100,5 & 120,6 & 114,5 & $9,80 \%$ \\
\hline Diciembre & 130,8 & 134,7 & 137,5 & 138,0 & 141,0 & 136,4 & $11,67 \%$ \\
\hline Total 2016 & 1190,3 & 1165,1 & 1200,1 & 1076,6 & 1211,4 & $1.168,7$ & $100,00 \%$ \\
\hline
\end{tabular}

Fuente: DANE

Tomado de: https://www.dane.gov.co/index.php/estadisticas-por-tema/industria/encuestaanual-manufacturera-enam 
Ilustración 37. Proyección de ventas Luzinda SAS

\begin{tabular}{|lr|r|r|r|r|}
\cline { 2 - 7 } \multicolumn{1}{c|}{} & \multicolumn{6}{c|}{ Proyección de cantidades vendidas por año Luzinda SAS } \\
\hline MES & AÑ̃ 1 & \multicolumn{1}{c|}{ AÑ O 2 } & \multicolumn{1}{c|}{ AÑ 3 } & \multicolumn{1}{c|}{ AÑO 4 } & \multicolumn{1}{c|}{ AÑO 5 } \\
\hline ENERO & 172 & 180 & 189 & 199 & 209 \\
\hline FEBRERO & 176 & 185 & 194 & 204 & 214 \\
\hline MARZO & 191 & 200 & 210 & 221 & 232 \\
\hline ABRIL & 197 & 207 & 217 & 228 & 239 \\
\hline MAYO & 198 & 208 & 218 & 229 & 241 \\
\hline JUNIO & 169 & 178 & 187 & 196 & 206 \\
\hline JULIO & 190 & 199 & 209 & 220 & 231 \\
\hline AGOSTO & 186 & 195 & 205 & 215 & 226 \\
\hline SEPTIEMBRE & 209 & 220 & 231 & 242 & 254 \\
\hline OCTUBRE & 224 & 236 & 247 & 260 & 273 \\
\hline NOVIEMBRE & 239 & 250 & 263 & 276 & 290 \\
\hline DICIEMBRE & 284 & 298 & 313 & 329 & 345 \\
\hline TOTAL & $\mathbf{2 . 4 3 5}$ & $\mathbf{2 . 5 5 7}$ & $\mathbf{2 . 6 8 5}$ & $\mathbf{2 . 8 1 9}$ & $\mathbf{2 . 9 6 0}$ \\
\hline
\end{tabular}

Fuente: Autoras

Como se observa en la Ilustración 34. Proyección de ventas, Luzinda para el año uno se proyecta con una venta de 2.435 unidades, estas van creciendo positiva mente hasta el año cinco donde presenta ventas por 2.960 unidades.

\section{Presupuesto de fabricación}

El presupuesto de fabricación para la empresa Luzinda SAS representado en la ilustración 35, se construyó partiendo de las necesidades de ventas a satisfacer por Luzinda año a año, en él se establece cuantas unidades se deben fabricar para siempre tener disponibilidad del producto y no afectar el curso de las ventas, para la proyección hasta el año cinco se empleó el índice de la inflación. 
Luzinda debe fabricar para el primer año 2.939, para el año siguiente esta cifra disminuye puesto que ya para este año se cuentan con inventarios del año anterior.

Ilustración 38. Presupuesto de fabricación

\begin{tabular}{|c|c|c|c|c|c|}
\hline & \multicolumn{5}{|c|}{ PLAN FABRICACION } \\
\hline & AÑO 1 & AÑO 2 & AÑO 3 & AÑO 4 & AÑO 5 \\
\hline Inventario Final* & 504 & 528 & 552 & 579 & 608 \\
\hline Unidades a Vender & 2.435 & 2.557 & 2.685 & 2.819 & 2.960 \\
\hline Total Necesidades & 2.939 & 3.085 & 3.236 & 3.398 & 3.568 \\
\hline Inventario Inicial de Productos Terminados & 0 & 504 & 528 & 552 & 579 \\
\hline Unidades a producir & 2.939 & 2.581 & 2.708 & 2.847 & 2.989 \\
\hline
\end{tabular}

Fuente: Autoras

\section{Estado de costos}

Para determinar el costo de ventas, se construye el Estado de Costos, en el que se reflejan

los costos de las materias primas, los costos de la mano de obra, costos de fabricación y costos de los inventarios (proceso y terminado.

Como se observa en la ilustración 40, los costos de ventas en el año uno son los más altos, esto dado el año 1 se inicia con inventarios en 0 , por tanto, la compra de materia prima debe ser más alta que para los años siguientes. 
Ilustración 39. Estado de costos

ESTADO DE COSTOS PARA LA EMPRESA LUzinda SAS

\begin{tabular}{|l|r|r|r|r|r|}
\hline PERIODOS & \multicolumn{1}{|c|}{ AÑO 1 } & \multicolumn{1}{|c|}{ AÑO 2 } & \multicolumn{1}{c|}{ AÑO 3 } & \multicolumn{1}{c|}{ AÑO 4 } & AÑO 5 \\
\hline Inventario Inicial de Materia Prima & - & 27.380 .884 & 36.367 .671 & 42.013 .100 & 18.857 .788 \\
\hline Compras de MP & 186.211 .975 & 195.648 .863 & 214.475 .270 & 227.303 .698 & 265.187 .647 \\
\hline MP disponible & 186.211 .975 & 223.029 .747 & 250.842 .941 & 269.316 .797 & 284.045 .436 \\
\hline Inv. Final MP & 27.380 .884 & 36.367 .671 & 42.013 .100 & 18.857 .788 & 8.751 .192 \\
\hline MP Consumida & 158.831 .091 & 186.662 .076 & 208.829 .842 & 250.459 .009 & 275.294 .243 \\
\hline MP Indirecta & 9.118 .235 & 10.791 .417 & 12.082 .533 & 14.499 .040 & 15.858 .325 \\
\hline MP Directa & 149.712 .856 & 175.870 .658 & 196.747 .308 & 235.959 .969 & 259.435 .918 \\
\hline Mano de Obra Directa & 19.700 .568 & 20.646 .195 & 21.575 .274 & 22.654 .038 & 23.786 .740 \\
\hline CIF & 55.876 .662 & 59.743 .541 & 63.325 .818 & 68.304 .489 & 72.354 .047 \\
\hline MP indirecta & 9.118 .235 & 10.791 .417 & 12.082 .533 & 14.499 .040 & 15.858 .325 \\
\hline MO indirecta & 16.902 .427 & 17.663 .036 & 18.546 .188 & 19.473 .497 & 20.447 .172 \\
\hline Otros CIF & 29.856 .000 & 31.289 .088 & 32.697 .097 & 34.331 .952 & 36.048 .549 \\
\hline COSTOS DE FABRICACION & 225.290 .086 & 256.260 .395 & 281.648 .400 & 326.918 .496 & 355.576 .704 \\
\hline Inv. Inicial PP & - & 15.576 .636 & 136.967 .421 & 276.848 .976 & 453.001 .960 \\
\hline Inv. Final PP & 15.576 .636 & 136.967 .421 & 276.848 .976 & 453.001 .960 & 658.539 .836 \\
\hline Costos de Producción & 209.713 .449 & 134.869 .610 & 141.766 .846 & 150.765 .512 & 150.038 .828 \\
\hline Inv. Inicial PT & - & 26.158 .917 & 27.613 .028 & 29.600 .080 & 31.566 .210 \\
\hline Inv. Final PT & 26.158 .917 & 27.613 .028 & 29.600 .080 & 31.566 .210 & 34.608 .023 \\
\hline COSTOS DE VENTAS & $\mathbf{1 8 3 . 5 5 4 . 5 3 2}$ & $\mathbf{1 3 3 . 4 1 5 . 5 0 0}$ & $\mathbf{1 3 9 . 7 7 9 . 7 9 3}$ & $\mathbf{1 4 8 . 7 9 9 . 3 8 2}$ & $\mathbf{1 4 6 . 9 9 7 . 0 1 6}$ \\
\hline
\end{tabular}

Fuente: Autora

\section{Flujo de caja}

Como se observa en la ilustración 41 y 42, Luzinda $\boldsymbol{S A S}$ aumenta su flujo de efectivo año

tras año, por tanto, cuenta con el capital de trabajo necesario para que la empresa realice sus operaciones de manera óptima y de cumplimiento a sus objetivos. 
Ilustración 40. Flujo de caja

FLUJO DE CAJA LUZINDA SAS

AÑO 0 AÑO 1 AÑO 2
INGRESOS DE EFECTIVO
\begin{tabular}{|l|l|l|l|l|l|l|}
\hline Capital Social & 55.000 .000 & & & & & \\
\hline Recaudo de Clientes & & 365.262 .712 & 401.935 .088 & 441.023 .275 & 486.228 .161 & 536.066 .548 \\
\hline Otros ingresos & & & & & & AÑO 4 \\
\hline
\end{tabular}

\begin{tabular}{|l|l|l|l|l|l|l|}
\hline Total Entradas de Efectivo & 55.000 .000 & 365.262 .712 & 401.935 .088 & 441.023 .275 & 486.228 .161 & 536.066 .548 \\
\hline
\end{tabular}

SALIDAS DE EFECTIVO

\begin{tabular}{|c|c|c|c|c|c|c|}
\hline Pago a Proveedores & & 186.211.975 & 136.954 .204 & 208.827 .348 & 223.455 .169 & 253.822 .462 \\
\hline Pago MO general & & 36.602 .995 & 38.309 .231 & 40.121 .462 & 42.127 .535 & 44.233 .912 \\
\hline Pago de otros CIF & & 29.856 .000 & 31.289 .088 & 32.697 .097 & 34.331 .952 & 36.048 .549 \\
\hline Gastos de Administración & & 84.401 .800 & 86.976 .501 & 90.861 .994 & 95.373 .484 & 100.110 .548 \\
\hline Gastos de Ventas & & 15.900 .222 & 16.663 .432 & 17.413 .287 & 18.283 .951 & 19.198.149 \\
\hline impuestos & & & 20.351 .540 & 41.219 .914 & 48.242 .050 & 55.942 .836 \\
\hline \multicolumn{7}{|l|}{ Compra Inversiones } \\
\hline Compra PP y Equipo & 16.566 .600 & & & & & \\
\hline Total Salidas de Efectivo & 16.566 .600 & 352.972 .991 & 330.543 .996 & 431.141.102 & 461.814.142 & 509.356 .456 \\
\hline Deficit o Superavit de Tesoreria & 38.433 .400 & 12.289 .720 & 71.391 .092 & 9.882 .174 & 24.414 .020 & 26.710.091 \\
\hline Saldo Inivial de Disponible & - & 38.433 .400 & 50.723 .120 & 122.114 .213 & 131.996.387 & 156.410 .406 \\
\hline SALDO FINAL DE DISPONIBLE & 38.433 .400 & 50.723 .120 & 122.114.213 & 131.996.387 & 156.410 .406 & 183.120.497 \\
\hline
\end{tabular}

Fuente: Autoras

Ilustración 41. Saldos finales disponibles

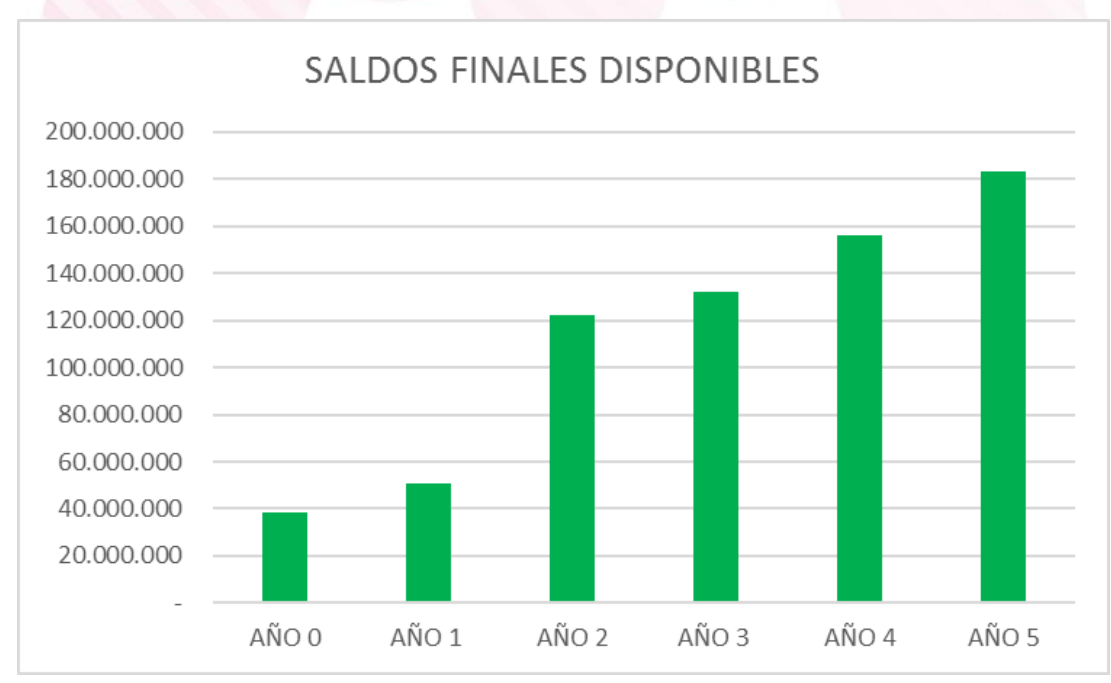

Fuente: Autoras 


\section{Estado de resultados}

El estado de resultados muestra que Luzinda es un proyecto viable, que genera utilidades desde el año 1 de operación generando $\$ 54.949 .157$ como utilidad del ejercicio, y como lo indica la proyección, todos los años presentan un aumento en la utilidad como se evidencia en la ilustración 43 y 44.

Ilustración 42. Estado de resultados

\section{ESTADO DE RESULTADOS EMPRESA LUZINDA SAS}

\begin{tabular}{|c|c|c|c|c|c|c|c|}
\hline & & AÑOO & AÑo 1 & AÑO 2 & AÑO 3 & AÑO 4 & AÑO 5 \\
\hline VENTAS & & & 365.262 .712 & 401.935 .088 & 441.023 .275 & 486.228 .161 & 536.066 .548 \\
\hline Costo de Ventas & & & 183.554 .532 & 133.415 .500 & 139.779 .793 & 148.799 .382 & 146.997 .016 \\
\hline UTILIDAD BRUTA EN VENTAS & & & 181.708 .180 & 268.519 .588 & 301.243 .482 & 337.428 .779 & 389.069 .532 \\
\hline GASTOS OPERACIONALES & & & 100.302 .022 & 103.639 .933 & 108.275 .281 & 113.657 .435 & 119.308 .697 \\
\hline ADMINISTRACION & & & 84.401 .800 & 86.976 .501 & 90.861 .994 & 95.373 .484 & 100.110 .548 \\
\hline VENTAS & & & 15.900 .222 & 16.663 .432 & 17.413 .287 & 18.283 .951 & 19.198.149 \\
\hline UTILIDAD OPERACIONAL & & & 81.406 .158 & 164.879 .655 & 192.968.201 & 223.771.344 & 269.760 .835 \\
\hline INGRESOS NO OPERACIONALES & & & - & - & - & - & - \\
\hline GASTOS NO OPERACIONALES & & & - & - & - & - & - \\
\hline UTILIDAD ANTES DE IMPUESTO & & & 81.406 .158 & 164.879 .655 & 192.968 .201 & 223.771 .344 & 269.760 .835 \\
\hline IMPORENTA & $25 \%$ & & 20.351 .540 & 41.219 .914 & 48.242 .050 & 55.942 .836 & 67.440 .209 \\
\hline UTILIDAD NETA & & & 61.054 .619 & 123.659 .741 & 144.726 .151 & 167.828 .508 & 202.320 .626 \\
\hline RESERVA LEGAL & $10 \%$ & & 6.105 .462 & 12.365 .974 & 14.472 .615 & 16.782 .851 & 20.232 .063 \\
\hline UTILIDAD DEL EJERCICIO & & & 54.949 .157 & 111.293 .767 & 130.253 .536 & 151.045 .657 & 182.088 .564 \\
\hline
\end{tabular}

Fuente: Autoras 
Ilustración 43. Utilidades del ejercicio

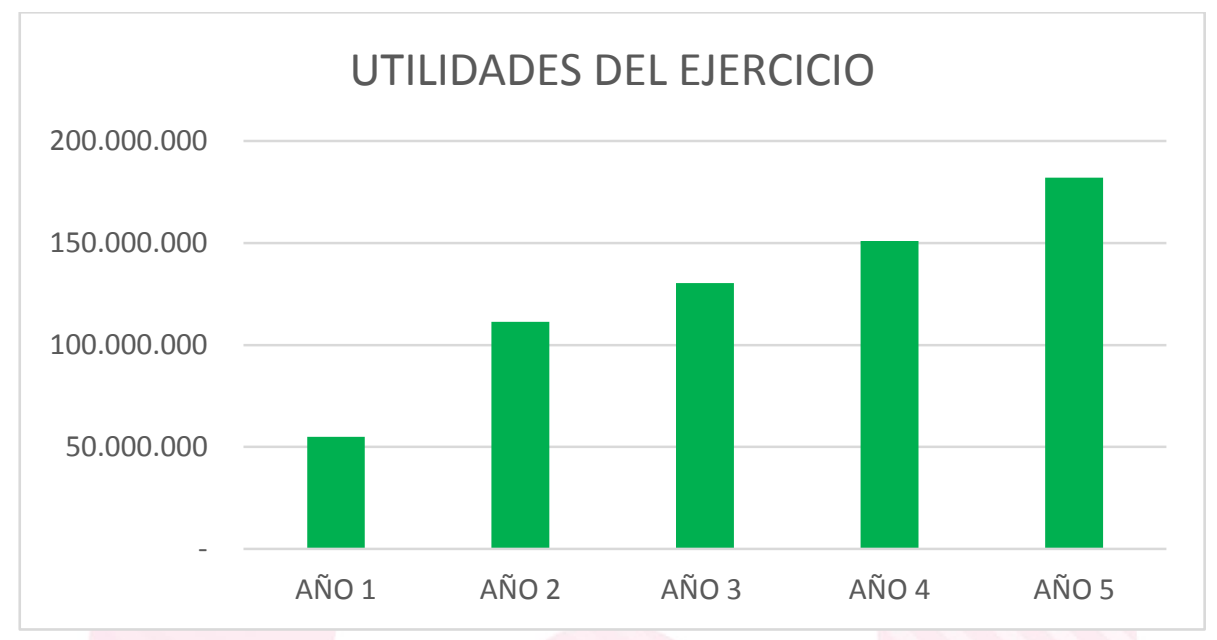

Fuente: Autoras

Balance general

Ilustración 44. Balance General

BALANCE GENERAL EMPRESA Luzinda SAS

\begin{tabular}{|c|c|c|c|c|c|c|}
\hline & AÑO 0 & AÑO 1 & AÑO 2 & AÑO 3 & AÑO 4 & AÑO 5 \\
\hline \multicolumn{7}{|l|}{ ACTIVOS } \\
\hline Disponible & 55.000 .000 & 50.723 .120 & 122.114 .213 & 131.996.387 & 156.410 .406 & 183.120.497 \\
\hline Inventarios & & 75.306 .958 & 202.981 .728 & 339.796 .828 & 482.396 .782 & 666.135 .783 \\
\hline Propiedad Planta y Equipo & & 16.566 .600 & 16.566 .600 & 16.566 .600 & 16.566 .600 & 16.566 .600 \\
\hline Depreciación Acumulada & & $(1.911 .160)$ & $(3.822 .320)$ & $(5.733 .480)$ & (7.644.640) & $(9.555 .800)$ \\
\hline TOTAL ACTIVOS & 55.000 .000 & 140.685 .518 & 337.840 .221 & 482.626 .334 & 647.729 .148 & 856.267 .080 \\
\hline \multicolumn{7}{|l|}{ PASIVOS } \\
\hline Proveedores & & - & 58.526 .640 & 63.728 .625 & 67.540 .431 & 78.797.169 \\
\hline \multicolumn{7}{|l|}{ Cuentas por Pagar } \\
\hline Impuestos por Pagar & & 20.351 .540 & 41.219 .914 & 48.242 .050 & 55.942 .836 & 67.440 .209 \\
\hline Obligaciones Laborales & & 4.279 .360 & 4.484 .769 & 4.686 .584 & 4.920 .913 & 5.166 .959 \\
\hline TOTAL PASIVO & - & 24.630 .899 & 104.231.323 & 116.657 .259 & 128.404 .180 & 151.404.337 \\
\hline \multicolumn{7}{|l|}{ PATRIMONIO } \\
\hline Capital Social & 55.000 .000 & 55.000 .000 & 55.000 .000 & 55.000 .000 & 55.000 .000 & 55.000 .000 \\
\hline Reservas & & 6.105 .462 & 12.365 .974 & 14.472 .615 & 16.782 .851 & 20.232 .063 \\
\hline Utilidad Acumulada & & & 54.949 .157 & 166.242 .924 & 296.496 .460 & 447.542 .117 \\
\hline Utilidad del Ejercicio & & 54.949 .157 & 111.293 .767 & 130.253 .536 & 151.045 .657 & 182.088 .564 \\
\hline TOTAL PATRIMONIO & 55.000 .000 & 116.054 .619 & 233.608 .898 & 365.969 .075 & 519.324 .968 & 704.862 .744 \\
\hline TOTAL PASIVO + PATRIMONIO & 55.000 .000 & 140.685 .518 & 337.840 .221 & 482.626 .334 & 647.729 .148 & 856.267 .080 \\
\hline
\end{tabular}

Fuente: Autoras 


\section{INDICADORES FINANCIEROS}

Ilustración 45. Indicadores de liquidez

\begin{tabular}{|l|l|c|c|c|c|c|}
\hline \multicolumn{2}{|c|}{ INDICADORES DELIQUIDEZ } & AÑ01 & AÑ02 & AÑ03 & AÑ04 & AÑ05 \\
\hline Capital de trabajo & $\begin{array}{l}\text { ACT. CORRIENTE-PAS. } \\
\text { CORRIENTE=UM }\end{array}$ & 101.399 .179 & 220.864 .618 & 355.135 .955 & 510.403 .008 & 697.851 .944 \\
\hline Liquidez & $\begin{array}{l}\text { ACTIVOCORRIENTE/ } \\
\text { PASIVOCORRIENTE } \\
\text { veces }\end{array}$ & 5,12 & 3,12 & 4,04 & 4,97 & 5,61 \\
\hline Prueba acida & $\begin{array}{l}\text { ACTIVOCORRIENTE- } \\
\text { INVENTARIOS)/ PASIV0 } \\
\text { CORRIENTE=veces }\end{array}$ & 2,06 & 1,17 & 1,13 & 1,22 & 1,21 \\
\hline Solidez & $\begin{array}{l}\text { ACTIVOTOTAL/ PASIVO } \\
\text { TOTAL =veces }\end{array}$ & 5,71 & 3,24 & 4,14 & 5,04 & 5,66 \\
\hline Endeudamiento Total & $\begin{array}{l}\text { PASIVOTOTAL/ACTIV0 } \\
\text { TOTAL }\end{array}$ & $17,51 \%$ & $30,85 \%$ & $24,17 \%$ & $19,82 \%$ & $17,68 \%$ \\
\hline
\end{tabular}

Fuente: Autoras

Ilustración 46. Indicadores de rentabilidad

\begin{tabular}{|l|l|c|c|c|c|c|}
\hline \multicolumn{2}{|c|}{ INDICADORES DE RENTABILIDAD } & AÑO1 & AÑO2 & AÑO3 & AÑO4 & AÑ05 \\
\hline Margen Operacional de Utilidad & $\begin{array}{l}\text { UTILIDAD OPERACIONAL / } \\
\text { INGRESOS OPERACIONALES }\end{array}$ & $22,29 \%$ & $36,39 \%$ & $35,68 \%$ & $38,25 \%$ & $42,63 \%$ \\
\hline Rentabilidad en ventas & $\begin{array}{l}\text { UTILIDAD LIQUIDA/ } \\
\text { INGRESOS OPERACIONALES }\end{array}$ & $16,72 \%$ & $27,29 \%$ & $26,76 \%$ & $28,69 \%$ & $31,97 \%$ \\
\hline Rentabilidad del activo & $\begin{array}{l}\text { UTILIDAD LIQUIDA/ TOTAL } \\
\text { ACTIVO }\end{array}$ & $43,40 \%$ & $36,60 \%$ & $29,99 \%$ & $25,91 \%$ & $23,63 \%$ \\
\hline Rentabilidad del patrimonio & $\begin{array}{l}\text { UTILIDAD LIQUIDA/ } \\
\text { PATRIMONIO }\end{array}$ & $52,61 \%$ & $52,93 \%$ & $39,55 \%$ & $32,32 \%$ & $28,70 \%$ \\
\hline
\end{tabular}

Fuente: Autoras 
Ilustración 47. TIR

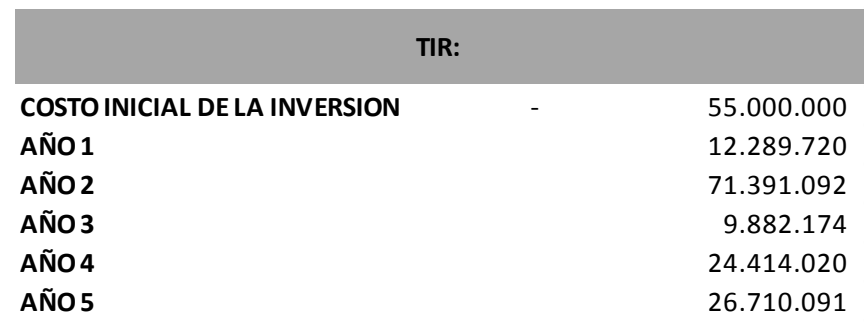

$T I R=$

Fuente: Autoras

Ilustración 48.VPN

\begin{tabular}{|c|c|c|}
\hline \multicolumn{3}{|c|}{ TASA: $10 \%$} \\
\hline \multicolumn{3}{|c|}{ VPN } \\
\hline COSTO INICIAL DE LA INVERSION & - & 55.000 .000 \\
\hline AÑO 1 & & 12.289 .720 \\
\hline AÑO 2 & & 71.391 .092 \\
\hline AÑO3 & & 9.882 .174 \\
\hline AÑO 4 & & 24.414 .020 \\
\hline AÑO 5 & & 26.710 .091 \\
\hline $\mathrm{VPN}=$ & & 55.857 .968 \\
\hline
\end{tabular}

Fuente: Autoras

\section{Interpretación de los indicadores}

Lo que podemos observar con los indicadores de liquidez e indicadores de rentabilidad es que la empresa año tras año, arroja cifras optimas y favorables.

La prueba acida por cada peso que la empresa debe a corto plazo cuenta con $\$ 2.06$ pesos para pagar en el año 1, \$1.17 pesos por cada peso que debe en el año 2, $\$ 1.13$ pesos por cada peso que debe en el año 3, cuenta con $\$ 1.22$ pesos para pagar cada peso que se debe en el año 4 y \$1.21 pesos por cada peso que se debe en el último año, lo cual nos demuestra que la empresa cuenta con el respaldo financiero para cubrir sus pasivos. 
Con el indicador de capital de trabajo se observa que la empresa dispone de recursos a corto plazo, para cubrir sus deudas corrientes, lo que indica que cuenta con los recursos necesarios para llevar a cabo de manera la proyección de fabricación y ventas.

Los márgenes de endeudamiento reflejan que la empresa posee pasivos, estos indican el compromiso del patrimonio frente a los acreedores, como lo reflejan los resultados estos compromisos con sus acreedores no son altos, para el año 1 es de $17.51 \%$, año 2 de $30.85 \%$, año 3 el $24.17 \%$, año 4 de $19.82 \%$ y para el año 5 de $17.68 \%$.

Con el indicador de margen operacional de utilidad se determina que, las ventas netas generan una utilidad operacional para todos los años de manera positiva, $22.29 \%$ para el primer año, 36.39\% para el segundo, 35.68\% para el tercero, $38.25 \%$ para el cuarto y 42.63\% para el quinto año, lo cual indica que los rendimientos de los activos operacionales aumentan en todos los años.

La TIR nos indica que, la tasa interna de retorno es de $45 \%$, que es mas alta que las tasas del $5.55 \%$ anual $-4.5 \%$ a seis meses ofrecida por el sistema bancario para un CDT, se tiene un VPN de \$ 55.857.968, esto indica que la opciòn de el proyecto Luzinda es viable, es una tasa que indica que se tiene una optima recuperaciòn de la inversiòn. 


\section{CONCLUSIONES}

El Business plan como opción de grado, permite al estudiante poner en práctica los conocimientos adquiridos durante su proceso de formación profesional, para llevar a cabo una idea de negocio, el presente trabajo es prueba de ello y muestra como resultado la viabilidad del proyecto Luzinda.

Con la investigación del comportamiento, situación y futuro del sector del calzado en la ciudad de Bogotá, se pudo determinar que este se ha ido consolidando, ya que logró hacer frente a la incursión asiática y de a pocos salir adelante, se encuentra mejorando, creciendo, gracias al trabajo de los empresarios quienes representados por la ACICAM Asociación Colombiana de Industriales del Calzado, el Cuero y sus Manufacturas, lograron que la productividad del sector creciera, además con la realización de la Feria Internacional del Cuero, Calzado, Marroquinería, Insumos y Tecnología, llevada a cabo en febrero se puede evidenciar por sus buenos resultados, que esta es una plataforma que sirve de vitrina para dar a conocer las nuevas propuestas del sector para dar apertura nuevos mercados.

Gracias a las encuestas realizadas a las mujeres de la muestra dirigidas al sector de Chapinero, se logró determinar que la frecuencia de compra de zapatos es de 3 a 6 meses, la red social preferida para conocer de un producto nuevo es Facebook, y la calidad predomina ante el precio y la marca al momento de comprar un zapato.

Los indicadores de liquidez y rentabilidad muestran que el negocio es viable y por tanto rentable, ya que la prueba acida arroja resultados positivos, al demostrar que la empresa cuenta con el respaldo para cubrir las deudas que tiene año tras año. 
Se logró determinar que la empresa dispone con recursos a corto plazo para cubrir las deudas corrientes, así como también que las ventas generan utilidad favorable para el negocio. 


\section{BIBLIOGRAFIA Y WEBGRAFIA}

RÁMIREZ DÍAZ, José Augusto. (2010). Evaluación Financiera de Proyectos. Colombia: Ediciones de la U.

Cadena Cuero, Calzado e Industria Marroquinera - DNP” Recuperado de: https://colaboracion.dnp.gov.co/CDT/Desarrollo\%20Empresarial/Cueros.pdf

FORERO MEDINA, L. (2016, junio 27). Cuero, calzado y marroquinería, Sector de talla mundial. Radio Santafé. Recuperado de:

http://www.radiosantafe.com/2016/06/27/cuero-calzado-y-marroquineria-sector-detalla-mundial/

(2016, mayo 17). "Confección y calzado pasan por un buen momento en el país". El tiempo. Recuperado de:

http://www.eltiempo.com/bogota/sector-de-la-confeccion-y-el-calzado-encolombia/16594997

(2017, febrero 9) "Producción de calzado muestra un crecimiento importante" Portafolio

Recuperado de:

http://www.portafolio.co/negocios/produccion-de-calzado-aumento-en-2017$\underline{503271}$

"Más de 13 mil personas Visitaron la feria IFLS+EICI" Recuperado de:

http://www.ifls.com.co/index.php?option=com_content\&view=article\&id=132

(2017, febrero 16). "2017 Será complejo para la industria del cuero y el calzado en Colombia" Dinero. Recuperado de:

http://www.dinero.com/edicion-impresa/negocios/articulo/perspectivas-de-laindustria-del-cuero-y-el-calzado-en-colombia/242008 
Calzado, Cuero y sus Manufacturas. Recuperado de: http://www.portafolio.co/negocios/produccion-de-calzado-aumento-en-2017$\underline{503271}$

ÚRSULA MENA LOZANO TORA (2008, noviembre) "Secretaria Distrital de Cultura, Recreación y Deportes, Vatorio de Culturas" Localidad de chapinero ficha Básica. Recuperado de: http://www.culturarecreacionydeporte.gov.co/observatorio/documentos/localidades/ chapinero.pdf

Imágenes 3 Edificios chapinero, Tomadas de: https://www.google.com.co/search

DANE.( Abril 2017) Tomado de:

http://www.sdp.gov.co/PortalSDP/InformacionTomaDecisiones/Estadisticas/Proyec cionPoblacion

"Calidad del producto determina la decisión de compra de los colombianos" Recuperado de: http://www.fenalco.com.co/node/4720 


\section{ANEXOS}

\section{Presupuestos de Materias primas}

\begin{tabular}{|c|c|c|c|c|c|c|c|c|c|c|}
\hline \multirow{3}{*}{ MATERIAS PRIMAS } & \multirow{3}{*}{$\begin{array}{c}\text { UNIDAD DE } \\
\text { MEDIDA }\end{array}$} & \multicolumn{5}{|c|}{ AÑO 1} & \multicolumn{4}{|c|}{ AÑO 2} \\
\hline & & \multirow{2}{*}{\begin{tabular}{|c|} 
VALOR \\
UNITARIO \\
\end{tabular}} & \multirow{2}{*}{$\begin{array}{l}\text { CANTIDAD } \\
\text { POR UNIDADC }\end{array}$} & \multirow{2}{*}{\begin{tabular}{|c|} 
TOTAL \\
COSTO UNIT.
\end{tabular}} & \multicolumn{2}{|c|}{$\begin{array}{l}\text { PRESUPUESTO } \\
\text { MATERIALES }\end{array}$} & \multirow{2}{*}{\begin{tabular}{|c|} 
VALOR \\
UNITARIO
\end{tabular}} & \multirow{2}{*}{\begin{tabular}{|c|} 
TOTAL \\
COSTO UNIT. \\
\end{tabular}} & \multicolumn{2}{|c|}{$\begin{array}{l}\text { PRESUPUESTO } \\
\text { MATERIALES }\end{array}$} \\
\hline & & & & & CANTIDAD & VALOR & & & CANTIDAD & VALOR \\
\hline \multicolumn{2}{|c|}{ MATERIA PRIMA DIRECTA } & \multicolumn{5}{|c|}{\begin{tabular}{|c|} 
MATERIA PRIMA DIRECTA \\
\end{tabular}} & \multicolumn{4}{|c|}{\begin{tabular}{|c|} 
MATERIA PRIMA DIRECTA \\
\end{tabular}} \\
\hline Cuero sintético & Metro & 56.000 & 0,20 & \begin{tabular}{|r|}
11.200 \\
\end{tabular} & 588 & 32.915 .628 & 58.688 & \begin{tabular}{|r|}
11.738 \\
\end{tabular} & 516 & 30.295 .003 \\
\hline Forro & Unidad & 2.000 & 2,00 & 4.000 & 5.878 & 11.755 .582 & 2.096 & 4.192 & 5.162 & 10.819 .644 \\
\hline Bondeado Forro & Par & 6.000 & 1,00 & 6.000 & 2.939 & 17.633 .372 & 6.288 & 6.288 & 2.581 & 16.229 .466 \\
\hline Ojales & Millar & 12 & 32,00 & 384 & 94.045 & 1.128 .536 & 13 & 402 & 82.593 & 1.038 .686 \\
\hline Suela TR & Unidad & 4.500 & 2,00 & 9.000 & 5.878 & 26.450 .058 & 4.716 & 9.432 & 5.162 & 24.344 .198 \\
\hline Cordones & Docena & 60 & 2,00 & 120 & 5.878 & 352.667 & 63 & 126 & 5.162 & 324.589 \\
\hline Empaque & Unidad & 3.800 & 1,0000 & 3.800 & 2.939 & 11.167 .802 & 3.982 & 3.982 & 2.581 & 10.278 .662 \\
\hline \multirow{2}{*}{\multicolumn{2}{|c|}{ MATERIA PRIMA INDIRECTA }} & 72.372 & 40,20 & 34.504 & 118.144 & 101.403 .646 & 75.846 & 36.160 & 103.757 & 93.330 .247 \\
\hline & & \multicolumn{5}{|c|}{ MATERIA PRIMA INDIRECTA } & \multicolumn{4}{|c|}{ MATERIA PRIMA INDIRECTA } \\
\hline Hilo & Carrete & 37.300 & 0,01 & \begin{tabular}{|r|}
194 \\
\end{tabular} & 15 & 570.028 & 39.090 & \begin{tabular}{|r|}
203 \\
\end{tabular} & \begin{tabular}{r|}
13 \\
\end{tabular} & 524.645 \\
\hline Pengante Montaje & Unidad & 43.000 & 0,0065 & 280 & 19 & 821.421 & 45.064 & 293 & 17 & 756.023 \\
\hline Pegante Blanco & Unidad & 39.000 & 0,0070 & 273 & 21 & 802.318 & 40.872 & 286 & 18 & 738.441 \\
\hline Tachuelas & Centenar & 52 & 10,00 & 520 & 29.389 & 1.528 .226 & 54 & 545 & 25.810 & 1.406 .554 \\
\hline Puntillas & Centenar & 45 & 10,00 & 450 & 29.389 & 1.322 .503 & 47 & 472 & 25.810 & 1.217 .210 \\
\hline \multirow[t]{3}{*}{ Activador } & Unidad & 55.000 & 0,0070 & 385 & 21 & 1.131 .475 & 57.640 & 403 & 18 & 1.041 .391 \\
\hline & & 174.397 & 20,03 & 2.101 & $\mathbf{5 8 . 8 5 3}$ & 6.175 .971 & 182.768 & 2.202 & $\mathbf{5 1 . 6 8 7}$ & 5.684 .262 \\
\hline & TOTALES & 246.769 & 60,23 & 36.605 & 176.997 & 107.579 .617 & 258.614 & 38.363 & 155.444 & 99.014 .509 \\
\hline
\end{tabular}

\begin{tabular}{|c|c|c|c|c|c|c|c|c|c|}
\hline \multirow{3}{*}{ MATERIAS PRIMAS } & \multirow{3}{*}{$\begin{array}{c}\text { UNIDAD DE } \\
\text { MEDIDA }\end{array}$} & \multicolumn{4}{|c|}{ AÑO 3} & \multicolumn{4}{|c|}{ AÑO 4} \\
\hline & & \multirow{2}{*}{$\begin{array}{c}\text { VALOR } \\
\text { UNITARIO }\end{array}$} & TOTAL & \multicolumn{2}{|c|}{$\begin{array}{l}\text { PRESUPUESTO } \\
\text { MATERIALES }\end{array}$} & \multirow{2}{*}{$\begin{array}{c}\text { VALOR } \\
\text { UNITARIO }\end{array}$} & TOTAL & \multicolumn{2}{|c|}{$\begin{array}{l}\text { PRESUPUESTO } \\
\text { MATERIALES }\end{array}$} \\
\hline & & & COSTO UNIT & CANTIDAD & VALOR & & сOSTO UNIT & CANTIDAD & VALOR \\
\hline \multicolumn{2}{|c|}{ MATERIA PRIMA DIRECTA } & \multicolumn{4}{|c|}{ MATERIA PRIMA DIRECTA } & \multicolumn{4}{|c|}{ MATERIA PRIMA DIRECTA } \\
\hline Cuero sintético & Metro & 61.329 & 12.266 & 542 & 33.221 .170 & 64.395 & 12.879 & 569 & 36.660 .340 \\
\hline Forro & Unidad & 2.190 & 4.381 & 5.417 & 11.864 .703 & 2.300 & 4.600 & 5.693 & 13.092 .978 \\
\hline Bondeado Forro & Par & 6.571 & 6.571 & 2.708 & 17.797 .055 & 6.900 & 6.900 & 2.847 & 19.639 .468 \\
\hline Ojales & Millar & 13 & 421 & 86.670 & 1.139 .012 & 14 & 442 & 91.088 & 1.256 .926 \\
\hline Suela TR & Unidad & 4.928 & 9.856 & 5.417 & 26.695 .583 & 5.175 & 10.349 & 5.693 & 29.459 .202 \\
\hline Cordones & Docena & 66 & 131 & 5.417 & 355.941 & 69 & 138 & 5.693 & 392.789 \\
\hline Empaque & Unidad & 4.162 & 4.162 & 2.708 & 11.271 .468 & 4.370 & 4.370 & 2.847 & 12.438 .330 \\
\hline \multirow{2}{*}{\multicolumn{2}{|c|}{ MATERIA PRIMA INDIRECTA }} & 79.259 & 37.787 & 108.879 & 102.344 .932 & 83.222 & 39.677 & 114.429 & 112.940 .033 \\
\hline & & \multicolumn{4}{|c|}{ MATERIA PRIMA INDIRECTA } & \multicolumn{4}{|c|}{ MATERIA PRIMA INDIRECTA } \\
\hline Hilo & Carrete & 40.849 & \begin{tabular}{r|}
212 \\
\end{tabular} & 14 & 575.319 & 42.892 & 223 & 15 & 634.879 \\
\hline Pengante Montaje & Unidad & 47.092 & 306 & 18 & 829.046 & 49.446 & 321 & 19 & 914.872 \\
\hline Pegante Blanco & Unidad & 42.711 & 299 & 19 & 809.766 & 44.847 & 314 & 20 & 893.596 \\
\hline Tachuelas & Centenar & 57 & 569 & 27.084 & 1.542 .411 & 60 & 598 & 28.465 & 1.702 .087 \\
\hline Puntillas & Centenar & 49 & 493 & 27.084 & 1.334 .779 & 52 & 517 & 28.465 & 1.472 .960 \\
\hline Activador & Unidad & 60.234 & 422 & 19 & 1.141 .978 & 63.245 & 443 & 20 & 1.260 .199 \\
\hline \multirow{2}{*}{\multicolumn{2}{|c|}{ TOTALES }} & 190.993 & 2.301 & 54.238 & 6.233 .300 & 200.542 & 2.417 & 57.003 & 6.878 .593 \\
\hline & & 270.252 & 40.089 & 163.118 & 108.578 .232 & 283.764 & 42.093 & 171.433 & 119.818 .625 \\
\hline
\end{tabular}




\begin{tabular}{|c|c|c|c|c|c|}
\hline \multirow{3}{*}{ MATERIAS PRIMAS } & \multirow{3}{*}{$\begin{array}{l}\text { UNIDAD DE } \\
\text { MEDIDA }\end{array}$} & \multicolumn{4}{|c|}{ AÑO 5} \\
\hline & & \multirow{2}{*}{$\begin{array}{c}\text { VALOR } \\
\text { UNITARIO }\end{array}$} & \multirow{2}{*}{\begin{tabular}{|c|} 
TOTAL \\
COSTO UNIT. \\
\end{tabular}} & \multicolumn{2}{|c|}{$\begin{array}{c}\text { PRESUPUESTO } \\
\text { MATERIALES }\end{array}$} \\
\hline & & & & CANTIDAD & VALOR \\
\hline \multicolumn{2}{|c|}{ MATERIA PRIMA DIRECTA } & \multicolumn{4}{|c|}{ MATERIA PRIMA DIRECTA } \\
\hline Cuero sintético & Metro & 67.615 & 13.523 & 598 & 40.418 .025 \\
\hline Forro & Unidad & 2.415 & 4.830 & 5.978 & 14.435 .009 \\
\hline Bondeado Forro & Par & 7.244 & 7.244 & 2.989 & 21.652 .513 \\
\hline Ojales & Millar & 14 & 464 & 95.642 & 1.385 .761 \\
\hline Suela TR & Unidad & 5.433 & 10.867 & 5.978 & 32.478 .770 \\
\hline Cordones & Docena & 72 & 145 & 5.978 & 433.050 \\
\hline Empaque & Unidad & 4.588 & 4.588 & 2.989 & 13.713.258 \\
\hline \multirow{2}{*}{\multicolumn{2}{|c|}{ MATERIA PRIMA INDIRECTA }} & 87.383 & 41.661 & 120.151 & 124.516.386 \\
\hline & & \multicolumn{4}{|c|}{ MATERIA PRIMA INDIRECTA } \\
\hline Hilo & Carrete & 45.037 & 234 & 16 & 699.954 \\
\hline Pengante Montaje & Unidad & 51.919 & 337 & 19 & 1.008 .646 \\
\hline Pegante Blanco & Unidad & 47.089 & 330 & 21 & 985.189 \\
\hline Tachuelas & Centenar & 63 & 628 & 29.888 & 1.876 .551 \\
\hline Puntillas & Centenar & 54 & 543 & 29.888 & 1.623 .938 \\
\hline Activador & Unidad & 66.408 & 465 & 21 & 1.389 .370 \\
\hline \multirow{2}{*}{\multicolumn{2}{|c|}{ TOTALES }} & 210.569 & 2.537 & 59.853 & 7.583 .648 \\
\hline & & 297.952 & 44.198 & 180.004 & 132.100 .034 \\
\hline
\end{tabular}

Fuente: Autoras 


\section{Plan de fabricaciòn}

\begin{tabular}{|c|c|c|c|c|c|c|c|c|c|c|c|c|c|c|c|c|c|c|}
\hline & Mes 1 & Mes 2 & Mes3 & Mes 4 & Mes 5 & Mes 6 & Mes 7 & Mes 8 & Mes9 & Mes 10 & Mes 11 & Mes 12 & Total & AÑO1 & AÑO2 & AÑO3 & AÑO4 & AÑ 05 \\
\hline Inventario Fina $\left.\right|^{*}$ & 17 & 18 & 19 & 20 & 20 & 17 & 19 & 19 & 21 & 168 & 168 & 168 & 504 & 504 & 528 & 552 & 579 & 608 \\
\hline Unidades a Vender & 172 & 176 & 191 & 197 & 198 & 169 & 190 & 186 & 209 & 224 & 239 & 284 & 2.435 & 2.435 & 2.557 & 2.685 & 2.819 & 2,960 \\
\hline Total Necesidades & 189 & 194 & 210 & 217 & 218 & 186 & 209 & 204 & 230 & 392 & 406 & 452 & 2.939 & 2.939 & 3.085 & 3.236 & 3.398 & 3.568 \\
\hline Inventario Inicial de Productos Terminados & 0 & 0 & 0 & 19 & 18 & 19 & 20 & 20 & 17 & 19 & 19 & 21 & 0 & 0 & 504 & 528 & 552 & 579 \\
\hline Unidades a producir & 189 & 194 & 210 & 198 & 200 & 167 & 189 & 185 & 213 & 373 & 388 & 431 & 2.939 & 2.939 & 2.581 & 2.708 & 2.847 & 2.989 \\
\hline
\end{tabular}

Fuente: Autoras 


\section{Relación de costos fijos}

\begin{tabular}{|l|l|}
\hline \multicolumn{1}{|c|}{ COSTOS FIJOS } & \multicolumn{1}{|c|}{ MES } \\
\hline Depreciación maquinaria y equipo & 106.580 \\
\hline Arriendo & 3.800 .000 \\
\hline Teléfono e Internet & 130.000 \\
\hline Agua & 140.000 \\
\hline Luz & 120.000 \\
\hline Depreciación muebles y enseres & 52.683 \\
\hline Nómina Administrativa & 4.478 .800 \\
\hline Nómina de Ventas & 1.235 .852 \\
\hline Nómina operativa & 4.161 .966 \\
\hline Elementos de protección & 50.000 \\
\hline Gastos publicidad & 510.000 \\
\hline Honorarios Contador & 500.000 \\
\hline TotAL COSTOS FIJOS & 15.285 .881 \\
\hline
\end{tabular}

Fuente: Autoras 


\section{Depreciación}

\begin{tabular}{|c|c|c|c|c|c|}
\hline \multicolumn{4}{|c|}{ EQUIPOS DE OFICINA } & \multicolumn{2}{|c|}{ DEPRECIACION } \\
\hline CANTIDAD & CONCEPTO & & VALOR & VIDA UTIL & Depreciación anual \\
\hline 2 & Escritorios & $\$$ & 498.000 & 10 años & 49.800 \\
\hline 4 & Sillas & $\$$ & 405.000 & 10 años & 40.500 \\
\hline 1 & Archivador & $\$$ & 329.000 & 10 años & 32.900 \\
\hline 2 & Equipos de computo & $\$$ & 2.100 .000 & 5 años & 420.000 \\
\hline 1 & Impresora multifuncional & $\$$ & 400.000 & 5 años & 80.000 \\
\hline \multirow[t]{2}{*}{1} & Telefono & $\$$ & 45.000 & 5 años & 9.000 \\
\hline & SUBTOTAL & $\$$ & 3.777 .000 & & 632.200 \\
\hline \multicolumn{4}{|c|}{ EQUIPOS DE PRODUCCION } & & \\
\hline CANTIDAD & CONCEPTO & & VALOR & VIDA UTIL & Depreciación anual \\
\hline 1 & Mesa de corte & $\$$ & 500.000 & 10 años & 50.000 \\
\hline 1 & guarnecedora & $\$$ & 650.000 & 10 años & 65.000 \\
\hline 1 & Horno reactivador & $\$$ & 5.000 .000 & 10 años & 500.000 \\
\hline 4 & Estanteria metalica & $\$$ & 1.139 .600 & 10 años & 113.960 \\
\hline \multirow[t]{3}{*}{1} & Troqueladora & $\$$ & 5.500 .000 & 10 años & 550.000 \\
\hline & SUBTOTAL & $\$$ & 12.789 .600 & & 1.278 .960 \\
\hline & TOTAL & $\$$ & 16.566 .600 & & 1.911 .160 \\
\hline
\end{tabular}

Fuente: Autoras 